\title{
Development of organophosphate hydrolase activity in a bacterial homolog of human cholinesterase
}

\author{
Patricia M. Legler ${ }^{1 *}$, Susanne M. Boisvert ${ }^{2}$, Jaimee R. Compton ${ }^{3}$ and Charles B. Millard ${ }^{4}$ \\ ${ }^{1}$ Naval Research Laboratory, Center for Bio/Molecular Science and Engineering, Washington, DC, USA \\ ${ }^{2}$ Department of Chemistry, Texas State University, San Marcos, TX, USA \\ ${ }^{3}$ Nova Research Inc., Alexandria, VA, USA \\ ${ }^{4}$ United States Army Medical Research and Materiel Command, Fort Detrick, MD, USA
}

\section{Edited by:}

Carissa M. Soto, Naval Research

Laboratory, USA

\section{Reviewed by:}

Jiaoyang Jiang, University of Wisconsin-Madison, USA

Christian W. Gruber, Medical University of Vienna, Austria

Markus Kaiser, University of

Duisburg-Essen, Germany

\section{*Correspondence:}

Patricia M. Legler, Naval Research

Laboratory, Center for Bio/Molecular

Science and Engineering, 4555

Overlook Ave., Washington, DC 20375, USA

e-mail: patricia.legler@nrl.navy.mil
We applied a combination of rational design and directed evolution (DE) to Bacillus subtilis p-nitrobenzyl esterase (pNBE) with the goal of enhancing organophosphorus acid anhydride hydrolase (OPAAH) activity. DE started with a designed variant, pNBE $\mathrm{A} 107 \mathrm{H}$, carrying a histidine homologous with human butyrylcholinesterase $\mathrm{G} 117 \mathrm{H}$ to find complementary mutations that further enhance its OPAAH activity. Five sites were selected (G105, G106, A107, A190, and A400) within a $6.7 \AA$ radius of the nucleophilic serine $O \gamma$. All 95 variants were screened for esterase activity with a set of five substrates: pNP-acetate, pNP-butyrate, acetylthiocholine, butyrylthiocholine, or benzoylthiocholine. A microscale assay for OPAAH activity was developed for screening DE libraries. Reductions in esterase activity were generally concomitant with enhancements in OPAAH activity. One variant, A107K, showed an unexpected 7 -fold increase in its $k_{\text {cat }} / K_{m}$ for benzoylthiocholine, demonstrating that it is also possible to enhance the cholinesterase activity of pNBE. Moreover, DE resulted in at least three variants with modestly enhanced OPAAH activity compared to wild type pNBE. A107H/A190C showed a 50-fold increase in paraoxonase activity and underwent a slow time- and temperature-dependent change affecting the hydrolysis of OPAA and ester substrates. Structural analysis suggests that pNBE may represent a precursor leading to human cholinesterase and carboxylesterase 1 through extension of two vestigial specificity loops; a preliminary attempt to transfer the $\Omega$ loop of BChE into pNBE is described. Unlike butyrylcholinesterase and pNBE, introducing a $\mathrm{G} 143 \mathrm{H}$ mutation (equivalent to $\mathrm{G} 117 \mathrm{H}$ ) did not confer detectable OP hydrolase activity on human carboxylesterase 1 (hCE1). We discuss the use of pNBE as a surrogate scaffold for the mammalian esterases, and the importance of the oxyanion-hole residues for enhancing the OPAAH activity of selected serine hydrolases.

Keywords: organophosphate, cholinesterase, directed evolution, catalytic bioscavenger, nerve agent, hysteresis

\section{INTRODUCTION}

Butyrylcholinesterase (BChE; EC 3.1.1.8) and its genetically engineered variants are being developed as therapeutic enzyme "bioscavengers" of organophosphorus acid anhydrides (OPAA) to prevent or treat OPAA poisoning (Millard et al., 1995a; Doctor and Saxena, 2005; Saxena et al., 2006) and also have been investigated to reverse cocaine addiction (Xie et al., 1999; Zheng and Zhan, 2008; Masson and Rochu, 2009). OPAA compounds (Figure 1) are highly toxic or lethal primarily because they

Abbreviations: AtCh, acetylthiocholine; BME, beta-mercaptoethanol; $\mathrm{BtCh}$, butyrylthiocholine; $\mathrm{BzCh}$, benzoylthiocholine; $\mathrm{CD}$, circular dichroism; $\mathrm{CE}$, carboxylesterase; DMSO, dimethylsulfoxide; DTNB, dithiobis(2-nitrobenzoic acid); DTT, dithiothreitol; EB, equilibration buffer; hCE1, human carboxylesterase 1 ; IPTG, isopropyl- $\beta$-thiogalactoside; $\Omega$-loop, residues between Cys-67-Cys-94 (TcAChE numbering); OPAA, organophosphorus acid anhydride inhibitors; OPAAH, organophosphorus acid anhydride hydrolase; paraoxon, diethyl $p$ nitrophenylphosphate; pNBE, p-nitrobenzylesterase; pNPA, p-nitrophenyl acetate; pNPB, p-nitrophenyl butyrate; SDS-PAGE, sodium dodecyl sulfate polyacrylamide gel electrophoresis; WT, wild type. rapidly, completely, and irreversibly inhibit essential biological stores of synaptic acetylcholinesterase (AChE; EC 3.1.1.7) leading to rigid paralysis, asphyxiation, and seizures (Shih et al., 2003). OPAA are archetypical irreversible inhibitors of serine hydrolases (Scheme S1), but in some cases the inhibition is slowly reversed (half-time of hours or days) because the phosphylated esterase undergoes spontaneous hydrolysis of the covalent adduct to yield reactivated enzyme (Main, 1979). Human BChE has been proposed as a prophylactic antidote because it is able to react rapidly with essentially all toxic pesticides and military "nerve agents" in the blood stream to prevent inhibition of AChE (reviewed in Ashani, 2000; Doctor and Saxena, 2005; Nachon et al., 2013).

The primary limitation to employing natural human BChE as a therapeutic is that each enzyme molecule can react only once with an OPAA inhibitor molecule and therefore will require an estimated dose of $200-1820 \mathrm{mg} / 70 \mathrm{~kg}$ of BChE to confer protection against $2 \times \mathrm{LD}_{50}$ of most nerve agents (Ashani, 2000; Geyer et al., 2010). For therapeutic enzyme bioscavengers, catalyzed 


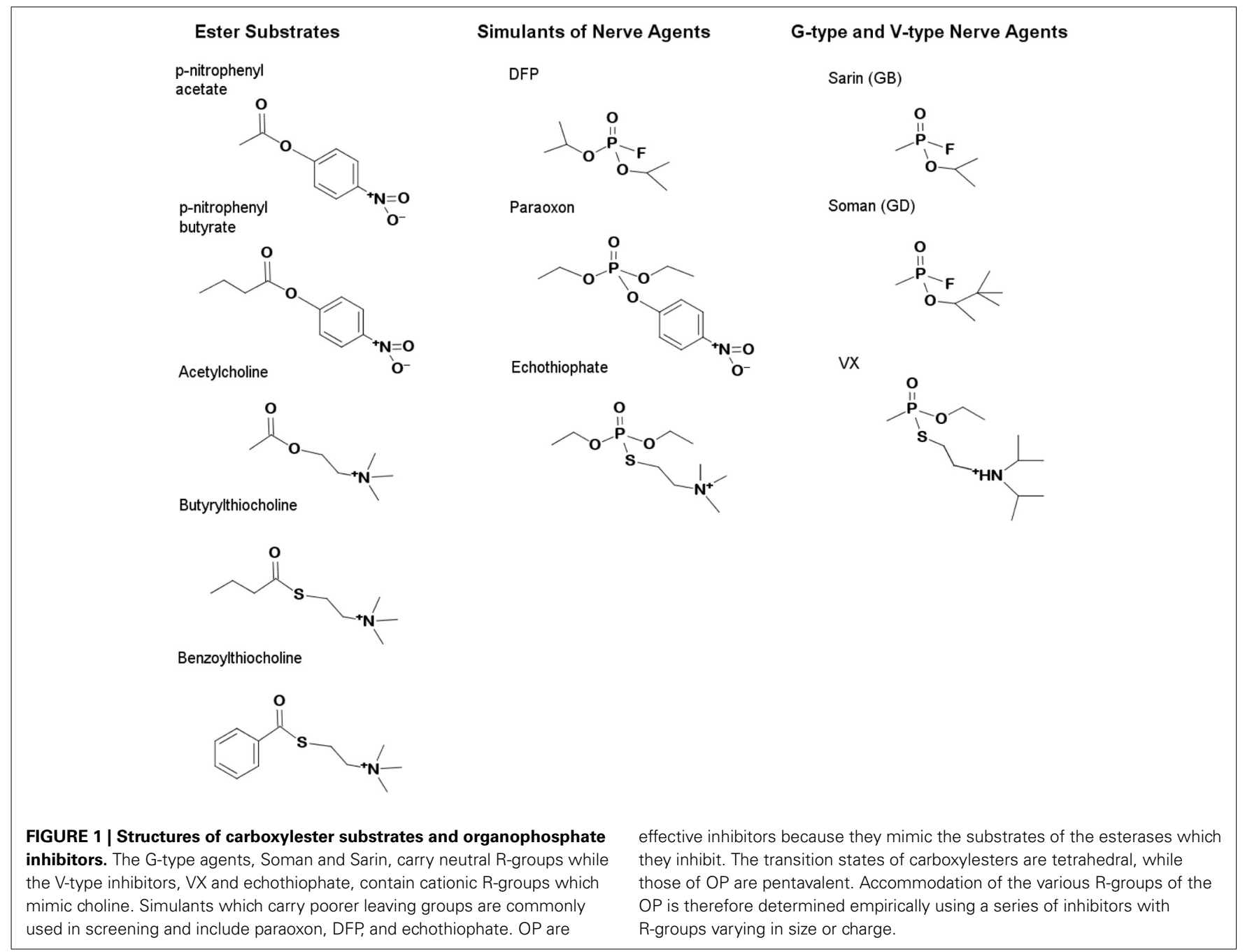

turnover could significantly enhance the rate of OPAA hydrolysis and reduce the amount of enzyme needed for protection. Using rational protein design, Millard and colleagues introduced a single histidine residue $(\mathrm{G} 117 \mathrm{H})$ into the oxyanion hole of human BChE to increase the rate of spontaneous reactivation and thereby convert OPAAs from inhibitors into xenobiotic substrates which could be hydrolyzed by the mutant enzyme (Millard et al., 1995a; Lockridge et al., 1997). G117H enhanced the hydrolysis of paraoxon or echothiophate by 100,000-fold (Lockridge et al., 1997), and a second mutation (G117H/E197Q) permitted hydrolysis of even the most toxic nerve agents known (soman, sarin, or $\mathrm{VX}$ ) by increasing the rate of spontaneous reactivation and simultaneously decreasing an unwanted side reaction known as "aging" (Scheme S1) (Shafferman et al., 1996; Millard et al., 1998).

Cholinesterase "aging" is an irreversible dealkylation of the phosphylated serine that proceeds through enzyme-catalyzed formation of a carbocation leaving group (Scheme S1) (Michel et al., 1967; Li et al., 2007; Masson et al., 2010). Dealkylation results in an anionic phosphoester adduct that is resistant to nucleophilic attack. Aging involves the same cholinesterase residues that stabilize the binding of positively charged leaving groups of choline esters or V-type nerve agents (VX and VR), including, Glu-197, and Trp-82 within the $\Omega$-loop of BChE (Figure S1, Figure 2) (Hosea et al., 1996; Masson et al., 1997a; Kua et al., 2003). Cholinesterases are predominantly found in higher eukaryotes and the $\Omega$-loop may have arisen specifically to bind and hydrolyze choline esters (Figure 2) because very few esterases react efficiently with cationic ligands (Cousin et al., 1996). Structurally related esterases [such as human carboxylesterase (hCE)] that lack the homologous Trp do not exhibit significant cholinesterase activity and do not undergo comparable aging after OPAA inhibition (Hemmert et al., 2010).

Human BChE and its variants offer several important advantages as therapeutic enzymes (Doctor and Saxena, 2005), and transgenic animals bearing the $\mathrm{G} 117 \mathrm{H}$ BChE variant have shown limited resistance to OPAA poisoning (Wang et al., 2004). A pegylated WT BChE enzyme (Protexia ${ }^{\circledR}$ ) has also shown protection in vivo against soman and VX (Lenz et al., 2007; Mumford and Troyer, 2011). In addition to BChE, other enzymes such as AChE, hCE, or the metalloenzyme paraoxonase (PON1) have shown promise as bioscavengers. Both BChE (Saxena et al., 2006; Lenz et al., 2007; Mumford and Troyer, 2011) and PON1 (Costa et al., 1990; Li et al., 1995; Valiyaveettil et al., 2011) have shown limited protection against nerve agent and OP-pesticide intoxication in 
A

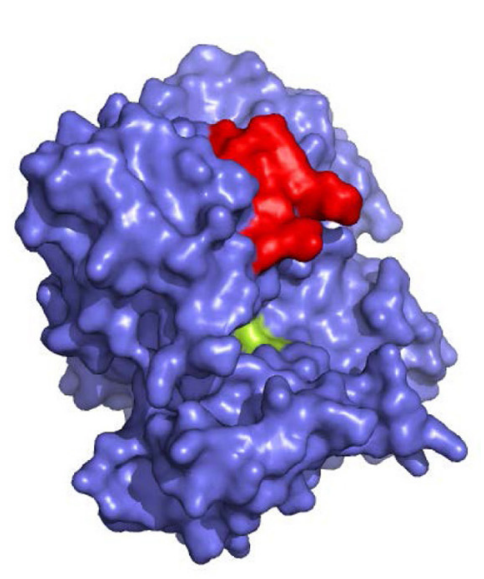

C

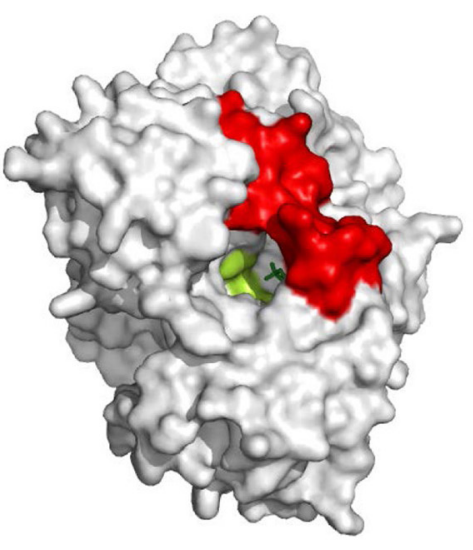

E

PNBE

pNBE Omega Loop

hCE1

TCAChE

$\mathrm{BChE}$

$\mathrm{BChE}$ G117H



D



|ा। I| $190 \quad 310 \quad 400$ ICPQ------PSDLLSLSYTELPRQSEDCLYVN...WIHGGAF...FGESAGG...RDEG..AFHAL ICCQN--IDQSE PGFHGSEMWNPNT DLSEDCLYVN...WIHGGAF ...FGE SAGG...RDEG..AFHAI MCTQDPKAGQLLSELFTNRKENI PLKLSEDCLYLN...WIHGGGL...FGESAGG...KQE F...GDHGD NCQQY--VDEQEPGESGSEMWNPNREMSEDCLYLN...WIYGGGE...FGESAGG...KDEG...VIHGY SCCQN--IDQSEPGFHGSEMWNPNTDLSEDCLYLN...WIYGGGF...FGESAGA...KDEG...VMHGY SCCQN--IDQSEPGFHGSEMWNPNTDLSEDCLYLN...WIYGGHF ...FGESAGA...KDEG...VMHGY

$\begin{array}{cccc}|| & || & \mid & || \\ 117 & 199 & 325 & 439 \\ 116 & 198 & & 438 \\ 115 & & & \end{array}$

FIGURE 2 | Comparison of pNBE and BChE. (A) Structure of pNBE (PDB 10E3) (Spiller et al., 1999). (B) Active site of WT pNBE. The catalytic triad, Glu-310, His-399, Ser-189, is shown in lime. The residues selected for $\mathrm{DE}(\mathrm{G} 105, \mathrm{G} 106, \mathrm{~A} 107, \mathrm{~A} 190$, and $\mathrm{A400})$ are shown in blue ball and stick representation. The $A 107$ residue is equivalent to $\mathrm{G} 117$ in butyrylcholinesterase. Structured residues between Cys-61 and Cys-82 corresponding to the $\Omega$-loop of BChE are shown in red. pNBE and BChE are structurally similar and two structures can be superposed with an rmsd $=2.1 \AA$ over $350 \mathrm{C}_{\alpha}$. (C) Structure of BChE (PDB 1POM) (Nicolet et al., 2003). The $\Omega$-loop of BChE is shown in red, choline is shown in dark green. The narrow gorge of BChE is partially formed by the $\Omega$-loop. The catalytic triad is found at the bottom of the gorge. (D) The $\Omega$-loop forms part of the choline binding site and carries Trp-82; this residue forms an energetically significant cation-pi interaction with cationic choline substrates (Ordentlich et al., 1993, 1995). Glu-197 also plays an important role in choline binding (Ordentlich et al., 1995; Masson et al., 1997b), and a residue equivalent to Glu-197 is present in pNBE. (E) Partial sequence alignment of pNBE, the pNBE $\Omega$-loop variant, hCE1, TCAChE, BChE, and BChE G117H variant. The $\Omega$-loop residues between Cys-65 and Cys-92 are shown in red and are unstructured in pNBE [PDB 1 QE3 (Spiller et al., 1999)]. The $\Omega$-loop of BChE was transferred to pNBE to form the chimeric variant. The $\Omega$-loop is well formed in hCE1, AChE, and BChE. The Trp residue of the choline binding site is notably absent from pNBE and hCE1. The roles of these residues in catalysis are shown in Figure $\mathbf{S 1}$. animal models. PON1 has been mutated to hydrolyze both Gtype (soman and sarin) and V-type (VX) nerve agents (Cherny et al., 2013; Kirby et al., 2013). While PON1 is able to hydrolyze selected $\mathrm{OP}$ nerve agents at much faster rates in vitro than $\mathrm{G} 117 \mathrm{H}$ or hCE, the $K_{\mathrm{m}}$ values for WT PON1 and its variants are in the millimolar range (Otto et al., 2010). High turnover numbers can be achieved by PON1 at saturating concentrations of OPAA (Kirby et al., 2013) but these concentrations are well above the levels of nerve agent that can be tolerated in living systems $\left(\mathrm{LD}_{50}^{\text {soman }}=113 \mu \mathrm{g} / \mathrm{kg}=0.00062 \mathrm{mmol} / \mathrm{kg}\right.$ in mice; Maxwell and 
Koplovitz, 1990) and the $\mathrm{IC}_{50}$ of AChE $\left(\mathrm{IC}_{50}^{\text {soman }}=0.88-2.53 \mathrm{nM}\right.$, $\mathrm{IC}_{50}^{\text {sarin }}=3.27-6.15 \mathrm{nM}$; Fawcett et al., 2009). Consequently, each class of enzyme bioscavenger has advantages and disadvantages (Trovaslet-Leroy et al., 2011), and efforts to improve binding and expand the substrate specificities of several candidates is ongoing (Otto et al., 2010; Trovaslet-Leroy et al., 2011; Kirby et al., 2013; Mata et al., 2014).

Unfortunately, the modest OPAA rate enhancements conferred on BChE by the G117H mutation have not been improved upon for the past two decades (Millard et al., 1995a, 1998; Lockridge et al., 1997). Emerging technologies for protein engineering, especially directed evolution (DE) or biological incorporation of unnatural amino acids into the active site to improve OPAAH rates, have not been applied to cholinesterases largely because these eukaryotic enzymes have complex tertiary structures with extensive post-/co-translational modifications (e.g., glycosylation, GPI-anchor, disulfides) and, therefore, are not amenable to facile manipulation and expression in prokaryotic systems (Masson et al., 1992; Ilyushin et al., 2013). In contrast, DE has been successfully applied to paraoxonase using variants of human PON1 which produce soluble and active enzyme in E. coli (Aharoni et al., 2004).

To explore a combination of rational design and DE methods on a bacterial enzyme that shares the cholinesterase fold, we selected Bacillus subtilis p-nitrobenzyl esterase (pNBE, EC 3.1.1.-; Spiller et al., 1999). We chose pNBE as a surrogate scaffold because: (i) the X-ray structures suggest that pNBE may represent a prokaryotic structural precursor to the cholinesterases (AChE or BChE) (Spiller et al., 1999), as well as to the related family of hCE (Figure S1); (ii) pNBE appears to have a more open active site (Figure 2) and was shown previously to permit DE modifications of substrate specificity loops without compromising protein folding (Giver et al., 1998; Spiller et al., 1999); and (iii) pNBE, like the family of hCE (Fleming et al., 2007), lacks the amino acid present in BChE and AChE that is known to promote the deleterious aging reaction (e.g., W82 of BChE) (Masson et al., 1997a). We created and screened a library of 162 pNBE variants to identify mutations which could enhance OPAAH activity and expand the substrate and inhibitor specificities of this enzyme. The mutations were then transferred to hCE1 to determine if pNBE could be used as a surrogate scaffold. We identified one pNBE variant with a three-order of magnitude enhancement in somanase activity compared with WT. Unexpectedly, the variant with the largest enhancement in OPAA activity also underwent a slow time- and temperature-dependent change in activity. We correlate our results with the solved X-ray structures of pNBE to understand possible mechanisms for engineered OPAAH activity, and discuss complications posed by hysteretic forms in the kinetic and structural analysis of mutant $\mathrm{pNBE}, \mathrm{AChE}$ and $\mathrm{BChE}$ (Masson et al., 2005; Badiou et al., 2008; Lushchekina et al., 2014).

\section{MATERIALS AND METHODS MATERIALS}

BugBuster $^{\mathrm{TM}}$ and the pTriEx-3 vector were from Novagen (San Diego, CA). Chelating Sepharose, Q-Sepharose, and PD-10 columns were from GE Healthcare Life Sciences (Piscataway, NJ). QuikChange ${ }^{\mathrm{TM}}$ kits were purchased from Stratagene (La
Jolla, CA). Benzoylthiocholine (BzCh) was purchased from TCI America (Portland, OR). The 96-well, clear polystyrene HIS-Select ${ }^{\circledR}$ High Capactiy (HC) Nickel Coated Plates were purchased from Sigma. All other chemicals were purchased from Sigma. Echothiophate was from Wyeth Pharmaceuticals Inc. (Philadelphia, PA).

\section{CONSTRUCTION OF THE DE LIBRARY}

Five sites in pNBE were selected for the directed-evolution library: G105, G106, A107, A190, and A400. The $\mathrm{C}_{\alpha}$ of each of the five residues was between 5.0 and $6.7 \AA$ from the Ser-189-O $\gamma$. The $\mathrm{A} 107 \mathrm{H}$ mutation was also present in each starting variant with the exception of the twenty variants of A107. The plasmids of the DE library were synthesized by GeneArt, Inc. (Regensberg, Germany). The pNBE expression vector (pTriEx-3, Novagen Inc.) contained an $\mathrm{N}$-terminal PreScission ${ }^{\mathrm{TM}}$ Protease cleavage site and a hexa-histidine tag preceding the pNBE sequence.

\section{CONSTRUCTION OF THE CHIMERIC BChE/pNBE $\Omega$-LOOP VARIANT}

The megaprimer method (Sarkar and Sommer, 1990) was used to construct the chimeric BChE-pNBE variant. A megaprimer containing a sequence from one of the known cholinesterase substrate specificity loops, in this case the " $\Omega$-loop" of BChE, was used to replace the homologous sequence in $\mathrm{pNBE}$. The variant was sequenced to confirm the substitution. Protein sequences are included in the Supplemental Information.

\section{SMALL SCALE PROTEIN EXPRESSION AND PURIFICATION}

All 95 constructs in the DE library expressed soluble protein under these conditions. Four milliliter cultures of LB containing $100 \mu \mathrm{g} / \mathrm{mL}$ Ampicillin were inoculated with frozen glycerol stocks and grown for $3 \mathrm{~h}$ at $37^{\circ} \mathrm{C}$ with shaking (200 rpm). Cultures were induced with $1 \mu \mathrm{L}$ of $1.0 \mathrm{M}$ IPTG overnight at $17^{\circ} \mathrm{C}$. Bacteria were pelleted and then lysed in $0.5 \mathrm{~mL}$ Lysis Buffer $(87.5 \%$ BugBuster $^{\mathrm{TM}}$, $2 \mathrm{mM}$ BME, $50 \mathrm{mM}$ Tris $\mathrm{pH} 7.6,375 \mathrm{mM} \mathrm{NaCl}$ ) at room temperature $\left(17-22^{\circ} \mathrm{C}\right)$ for at least $1 \mathrm{~h}$. Lysed bacteria were centrifuged at $4800 \times \mathrm{g}$ for $10 \mathrm{~min}$. Clarified lysates were then loaded onto nickel-charged Chelating Sepharose columns $(0.5 \mathrm{~mL}$ slurry per disposable column) equilibrated with three column volumes of equilibration buffer (EB; $50 \mathrm{mM}$ Tris $\mathrm{pH}$ 7.6, $500 \mathrm{mM} \mathrm{NaCl}, 2 \mathrm{mM}$ BME). After the supernatant was loaded, the columns were washed again with three column volumes of EB. To elute contaminants, the columns were washed with three column volumes of EB containing $60 \mathrm{mM}$ Imidazole. Proteins were isocratically eluted with $\mathrm{EB}$ containing $300 \mathrm{mM}$ Imidazole. Imidazole readily reacts with the carboxyl ester substrates used to assay the enzyme; thus, it was necessary to buffer exchange the enzymes with BioMax (10,000 NMWL) ultrafiltration units three times with $50 \mathrm{mM}$ HEPES pH 7.0, $150 \mathrm{mM} \mathrm{NaCl}$ to remove the imidazole. Purified enzymes ran as single bands in SDS-PAGE gels and were judged to be $\geq 90 \%$ pure.

\section{LARGE SCALE PROTEIN EXPRESSION AND PURIFICATION}

Large scale preps of selected variants were used for kinetic analysis. LB (1-3 L) containing $100 \mu \mathrm{g} / \mathrm{mL}$ Ampicillin was grown with shaking at $37^{\circ} \mathrm{C}$ and induced overnight with $0.2 \mathrm{mM}$ IPTG at $17^{\circ} \mathrm{C}$. Bacterial pellets were lysed in $40 \mathrm{~mL}$ of lysis buffer containing $\sim 30 \mathrm{mg}$ lysozyme and then sonicated for $1 \mathrm{~min}$ in an ice bath. 
Lysates were clarified by centrifugation $(30 \mathrm{~min}$ at $20,500 \times \mathrm{g})$. Supernatants were loaded onto a $20 \mathrm{~mL}$ nickel-charged Chelating Sepharose column. After loading, the column was washed with EB containing $60 \mathrm{mM}$ imidazole until the $A_{280}$ returned to a level baseline. Protein was eluted with EB containing $300 \mathrm{mM}$ imidazole. Fractions containing pNBE were combined and dialyzed against $50 \mathrm{mM}$ Tris $\mathrm{pH} 7.6,150 \mathrm{mM} \mathrm{NaCl}, 2 \mathrm{mM}$ BME. Protein was loaded onto a $30 \mathrm{~mL}$ Q-Sepharose column and eluted between 260 and $400 \mathrm{mM} \mathrm{NaCl}$ during the gradient.

\section{CARBOXYLESTERASE ASSAYS}

Steady state kinetic parameters for the enzyme catalyzed hydrolysis of p-nitrophenyl acetate (pNPA) and p-nitrophenyl butyrate ( $\mathrm{pNPB})$ were measured in triplicate at room temperature in $50 \mathrm{mM}$ HEPES 7.0, $150 \mathrm{mM} \mathrm{NaCl}(405 \mathrm{~nm})$. Substrate and inhibitors were dissolved in DMSO and accounted for less than $1 \%$ of the reaction volume.

Acetylthiocholine (AtCh), butyrylthiocholine (BtCh), or benzoylthiocholine $(\mathrm{BzCh})$ hydrolysis was measured in triplicate at $412 \mathrm{~nm}$ in cuvettes or a plate reader using Ellman's reagent (0.5 mM DTNB) (Ellman et al., 1961). All assays were done in $1 \times$ Sorensen's buffer $\left(53.4 \mathrm{mM} \mathrm{Na} \mathrm{HPO}_{4}, 13.4 \mathrm{mM} \mathrm{KH_{2 }} \mathrm{PO}_{4}\right)$ $\mathrm{pH} 7.4$ at room temperature $\left(22 \pm 2{ }^{\circ} \mathrm{C}\right)$. An extinction coefficient of $13.6 \mathrm{mM}^{-1} \mathrm{~cm}^{-1}$ was used for calculations. One Unit of activity (U) was defined as $1 \mu \mathrm{mol}$ product produced per min, and specific activity (S.A.) was defined as Units per milligram of enzyme (U/mg).

\section{PRIMARY ASSAY FOR SCREENING}

HIS-Select ${ }^{\circledR}$ plates were washed once with $200 \mu \mathrm{L}$ of binding buffer ( $50 \mathrm{mM}$ Hepes pH 7.0, $150 \mathrm{mM} \mathrm{NaCl})$. Each his-tagged protein $(\sim 25 \mathrm{mU})$ in the same buffer $(100 \mu \mathrm{L})$ was added to two wells and allowed to bind for $1 \mathrm{~h}$ at $37^{\circ} \mathrm{C}$. All wells contained enzyme after each plate setup. The OPAA inhibitor was added $(0.5-5 \mu \mathrm{L})$ to one of the two wells and incubated for $10 \mathrm{~min}$ at room temperature. Cautionary note: the OPAA compounds used in this study are highly toxic and must only be handled with adequate legal authority, training, and safety precautions. Liquid was removed by a multichannel pipettor, and plates were washed four times with $200 \mu \mathrm{L}$ of appropriate reaction buffer. Buffer (90 or $95 \mu \mathrm{L}$ ) and $0.5 \mathrm{M}$ EDTA (10 or $5 \mu \mathrm{L}$ ) were then added to each well to elute the protein. Plates were left at room temperature or at $37^{\circ} \mathrm{C}$, and aliquots of enzyme $(10 \mu \mathrm{L})$ were removed over time and assayed in separate 96-well plates using $5 \mathrm{mM}$ pNPbutyrate in binding buffer. Activity was measured at 4-6 time points to confirm reactivation of a single clone. For the clones which reactivated in the 96-well assay, large scale preps were then used to more accurately quantitate the enhancements in the rates of reactivation.

\section{LARGE SCALE DISCONTINUOUS SPONTANEOUS REACTIVATION ASSAYS}

Spontaneous reactivation was measured essentially as previously described (Millard et al., 1995a; Lockridge et al., 1997). Briefly, an aliquot of uninhibited enzyme or the OPAA-inhibited ( $>95 \%$ inhibited) enzyme was loaded onto PD-10 gel filtration columns equilibrated with $50 \mathrm{mM}$ Tris $\mathrm{pH} 7.6,150 \mathrm{mM} \mathrm{NaCl}, 2 \mathrm{mM}$ BME. At time $t=0$, the columns were loaded, and the protein was rapidly eluted; fractions were incubated at $37^{\circ} \mathrm{C}$, activity was measured for the uninhibited enzyme, and inhibited enzyme and percentages of reactivated enzyme were calculated. The pseudo first order rate constant for spontaneous reactivation due to the hydrolysis of the serinyl-phosphate adduct, $k_{\mathrm{r}}$, was determined by fitting the data to the following equation (Wang and Braid, 1967; Main, 1979):

$$
A_{t}=A_{\max }\left(1-e^{-k_{r} t}\right)
$$

where $A_{t}$ is the percent reactivated at time $t$ and $A_{\max }$ is the maximal percent reactivated at final observation time $>>t_{0}$. For the A107H/A190C variant, which exhibited a form of hysteresis (Hanozet et al., 1981; Uto and Brewer, 2008), the enzyme was incubated at $37^{\circ} \mathrm{C}$ for at least $2 \mathrm{~h}$ after exchanging the buffer using a PD-10 column equilibrated with $50 \mathrm{mM}$ Tris $\mathrm{pH} 7.6,150 \mathrm{mM}$ $\mathrm{NaCl}, 2 \mathrm{mM}$ BME. The enzyme was then inhibited, and rates of reactivation were measured.

\section{ORGANOPHOSPHATE INACTIVATION}

Aliquots of enzyme were inhibited with different concentrations of inhibitor, and the activity was measured discontinuously using pNP-butyrate at different time points. Data were plotted and fit to a single exponential decay equation to obtain $k_{o b s}$, the observed first order rate constant. A secondary plot was used to determine the maximal rate constant for inactivation, $k_{2}$, at infinite inhibitor concentration. The rate constant was determined by plotting $k_{o b s}$ vs. $[I]$ concentration and fitting the data to the following equation (or by extrapolation using the double-reciprocal form of the equation) from Kitz and Wilson (1962):

$$
k_{o b s}=\frac{k_{2}}{1+K_{p} /[I]}
$$

The apparent bimolecular rate constant, $k_{i}$, for formation of the covalent E-I complex from free enzyme and free inhibitor was calculated according to the following:

$$
k_{i}=k_{2} / K_{p}
$$

where $K_{p}$ is a Michaelis-type constant for the inhibitor.

\section{RESULTS}

\section{SELECTION OF RESIDUES FOR DIRECTED EVOLUTION (DE)}

Prior to the creation of the DE library, we produced the $\mathrm{A} 107 \mathrm{H}$ pNBE variant by analogy with BChE G117H (Millard et al., 1995a; Lockridge et al., 1997) and demonstrated that it possesses increased OPAAH activity (Table 1). The OPAAH activity of the pNBE A107H variant was found to be acid-catalyzed and 4-fold higher at $\mathrm{pH} 7.0$ than at $\mathrm{pH} 7.6$ (Table 1). At pH 7.0 the reactivation rate of the $\mathrm{A} 107 \mathrm{H}$ variant was 46 -fold higher when compared with WT and 18-fold higher at $\mathrm{pH}$ 7.6.

To identify mutations which could further enhance the OPAAH activity of $\mathrm{A} 107 \mathrm{H}$, we constructed a DE library of double mutants at five different sites: A107H/G105X, A107H/G106X, A107H/A190X, and A107H/A400X (where X stands for any amino acid). We also examined the A107X single mutation variants of pNBE. Each residue selected for DE (G105, G106, A107, 
Table 1 | pH dependence of reactivation rates after inhibition with ethyl paraoxon.

\begin{tabular}{lcccc}
\hline Enzyme & Inhibitor & $\mathbf{p H}$ & $\mathbf{\%}$ Reactivation & $\begin{array}{c}\boldsymbol{k}_{\text {reactivation }} \\
(\mathbf{1} / \mathbf{h})\end{array}$ \\
\hline WT & & & & $0.03 \pm 0.01$ \\
& Paraoxon & 7.6 & $110 \pm 10 \%$ & $0.05 \pm 0.01$ \\
& Paraoxon & 7.0 & $91 \pm 8$ & $0.035 \pm 0.007$ \\
& Paraoxon & 6.5 & $88 \pm 6$ & $0.042 \pm 0.005$ \\
& Paraoxon & 6.0 & $52 \pm 2$ & $0.53 \pm 0.09$ \\
A107H & Paraoxon & 7.6 & $102 \pm 5$ & $2.3 \pm 0.3$ \\
\hline BChE $\Omega$ Loop & Paraoxon & 7.0 & $90 \pm 10$ & $1.0 \pm 0.1$ \\
Mutant with A107H & Paraoxon & 7.6 & $86 \pm 4$ & \\
\hline
\end{tabular}

Rates were measured in $50 \mathrm{mM}$ Tris pH 7.6, $150 \mathrm{mM} \mathrm{NaCl}, 2 \mathrm{mM} \mathrm{BME;} 50 \mathrm{mM}$ Hepes 7.0, $150 \mathrm{mM} \mathrm{NaCl}, 2 \mathrm{mM} \mathrm{BME;} 50 \mathrm{mM}$ MES pH 6.5, $150 \mathrm{mM} \mathrm{NaCl}, 2 \mathrm{mM}$ $B M E$; or $50 \mathrm{mM}$ MES pH 6.0, $150 \mathrm{mM} \mathrm{NaCl}, 2 \mathrm{mM} \mathrm{BME}$ at $37^{\circ} \mathrm{C}$.

A190, or A400) was within $6.7 \AA$ of the O $\gamma$ of the nucleophilic Ser189 in pNBE and was conserved in BChE and hCE1 (Figure 2). Based upon the X-ray structure of pNBE, we concluded that the backbone NH groups of G106, A107, and A190 form a 3-point oxyanion hole (Figure S1). Gly-105 is situated near the oxyanion hole, but is not part of the oxyanion hole. The corresponding G105A variant in human AChE affected the turnover number of the substrate, but not the $K_{\mathrm{m}}$; this substitution was suggested to affect the conformational mobility of the adjacent residues of the oxyanion hole (Ordentlich et al., 1998). The side-chain of Ala190 was hypothesized to exert an effect on the polarity and/or orientation of the backbone $\mathrm{NH}$ groups of A107 and G106 and thereby affect TS stabilization. The oxyanion hole is the primary source of transition state stabilization in serine hydrolases (Bryan et al., 1986). The A190 side-chain is situated directly behind the loop carrying A107 and G106. The $\mathrm{C}_{\beta}$ of $\mathrm{A} 190$ is 3.6-3.7 $\AA$ away from the backbone NH of A107 and G106 (Figures S1B,D). The A400 residue is located on a loop of pNBE. The A400T mutation in $\mathrm{pNBE}$ was shown previously to project into the active site ( $6.7 \AA$ from the Ser-189-O $\gamma$ ) and enhance the thermostability of pNBE in DE experiments by Spiller et al. (1999). Spiller et al. proposed that the Thr side-chain of residue- 400 may stabilize His399 of the catalytic triad. A400 was also near the choline leaving group in overlays of pNBE with a BChE-choline co-crystal structure (1P0M) (Nicolet et al., 2003) (Figure S1C). We selected it here to find variants which might stabilize a particular conformer of His-399 or stabilize the alkyl groups of the soman pinacolyl group, the DFP iso-propyl groups, or, alternatively, the cationic choline-like leaving groups of V-type nerve agents and simulants (e.g., echothiophate).

\section{SUBSTRATE SPECIFICITY}

Five substrates were tested with single point assays and the DE library of variants to determine if the mutations altered substrate specificities: pNPA, pNPB, AtCh, BtCh, and BzCh (Figure S2). WT pNBE had the highest substrate specificity for pNP-butyrate as judged by the bimolecular rate constant, $k_{\text {cat }} / K_{\mathrm{m}}=14,000 \pm$ $2000 \mathrm{~min}^{-1} \mathrm{mM}^{-1}$. A detectible level of CE activity is needed to measure reactivation rates by the discontinuous method.
All 95 of the variants had detectable levels of CE activity when pNP-butyrate was used as the substrate. This allowed the use of a common substrate for activity measurements at different time points during reactivation experiments. No significant enhancement in the substrate specificities of the DE library variants for pNPA or pNPB was observed.

\section{CHARACTERIZATION OF VARIANTS WITH ENHANCED CHOLINESTERASE ACTIVITY}

Ideally, universal OP bioscavenging enzymes should scavenge both G-type and V-type agents (Figure 1). V-type agents, such as VX and VR, and V-type simulants like echothiophate mimic positively charged choline esters (Scheme S1) and readily inhibit AChE and BChE. Echothiophate and VX are slowly turned over by the BChE G117H variant (Millard et al., 1995a). Cholinesterase activity can only be found in a subset of esterases, typically those of eukaryotes (Cousin et al., 1996). The cationic choline esters are accommodated by two key residues at the bottom of the gorge of BChE and AChE, Trp-84/82, and Glu-199/197 (TcAChE/BChE numbering) (Ordentlich et al., 1995). These residues also play a role in the binding specificity of tetrahedral cationic V-type agents in AChE (Hosea et al., 1996), as well as in the unfavorable "aging" process (Shafferman et al., 1996). A residue within the peripheral anionic site (PAS) at the top of the gorge, Asp-72/70, also plays a role in V-type agent binding (Hosea et al., 1996), but is relatively distant from the choline binding pocket $(\sim 7 \AA)$; hCE1 and pNBE lack a homologous Asp residue (Figure 2E). Since hCE1 and pNBE are structurally similar to AChE and BChE (Figure S1A) but are not known to hydrolyze choline esters or become inhibited by V-type agents, we also examined the DE library for the development of cholinesterase activity and susceptibility to inhibition by echothiophate (last section).

Cholinesterases contain an omega-shaped loop between the disulfide bonded cysteines, Cys-67 and Cys-94 (TcAChE numbering) (Figure 2, Figure S1). The $\Omega$-loop carries Asp-72/70 and Trp-84/82 of the choline binding site. To determine if a cholinesterase $\Omega$-loop could be inserted, we substituted the $\Omega$ loop sequence of $\mathrm{BChE}$ into the $\mathrm{pNBE} \mathrm{A} 107 \mathrm{H}$ variant. The chimeric variant folded as a functional esterase (Table 2). The $K_{\mathrm{m}}$ and $k_{\text {cat }}$ values for PNPA were similar to those of the WT enzyme. However, the loop insertion alone did not confer cholinesterase activity, and the $k_{\text {cat }}$ and $K_{\mathrm{m}}$ for $\mathrm{BzCh}$ and $\mathrm{BtCh}$ were similar to those of the A107H pNBE variant (Table 3). Thus, the DE library was made with the A107H pNBE variant, rather than the loop-insertion variant.

All 95 variants were initially examined for cholinesterase activity using single point assays (Figure S2). To determine if the pNB-esterase variants could bind and turnover cationic OPAA like echothiophate, we first looked for cholinesterase activity. AChE, BChE, hCE1, and pNB-esterase all share the same fold (Figure S1A). Steady state kinetic parameters for the variants which showed significant increases in cholinesterase activity are shown in Table 3. Unexpectedly, the variant which showed the largest increase in cholinesterase activity was a single mutant with a positively charged lysine residue, $\mathrm{A} 107 \mathrm{~K}$. This variant showed a 7 -fold increase in the $k_{\mathrm{cat}} / K_{\mathrm{m}}$ and an 8 -fold increase in the $k_{\mathrm{cat}}$ of benzoylthiocholine, while the $K_{\mathrm{m}}$ was similar to WT. Substitution of $\operatorname{Arg}(A 107 R)$ in place of Lys did not significantly enhance 
benzoylthiocholinesterase activity, but resulted in a 3-fold higher $K_{\mathrm{m}}$ suggesting that the larger Arg side-chain may interfere with substrate binding. Substitution of A107 by the neutral residue, Gln, and by hydrophobic residues yielded similar $K_{\mathrm{m}}$ values and no enhancement of $k_{\text {cat }}$. Substitution of A107 by His also did not confer significant cholinesterase activity.

Butyrylthiocholinesterase activity was the highest in the A107S, A107T, A107H/A190R, and A107H/A400D variants

Table 2 | Substrate specificities of pNBE and selected variants.

\begin{tabular}{llccc}
\hline Enzyme & Substrate & $\boldsymbol{k}_{\text {cat }}(\mathbf{1} / \mathbf{m i n})$ & $\boldsymbol{K}_{\mathbf{m}}(\mathbf{m M})$ & $\begin{array}{c}\boldsymbol{k}_{\text {cat }} / \boldsymbol{K}_{\mathbf{m}} \\
\left(\mathbf{1} / \mathbf{m i n} \mathbf{m M}^{*} \mathbf{m}\right.\end{array}$ \\
\hline WT & pNPA & $370 \pm 30$ & $1.2 \pm 0.3$ & $300 \pm 80$ \\
& pNPB & $1100 \pm 40$ & $0.08 \pm 0.01$ & $14000 \pm 2000$ \\
A107H & pNPA & $130 \pm 10$ & $5.6 \pm 0.7$ & $23 \pm 3$ \\
& pNPB & $520 \pm 20$ & $0.12 \pm 0.02$ & $4300 \pm 700$ \\
A107H/A190C & pNPA & $70 \pm 10$ & $0.9 \pm 0.4$ & $70 \pm 30$ \\
A107H/A400T & pNPB & $460 \pm 10$ & $0.12 \pm 0.02$ & $3800 \pm 600$ \\
A107H/A400V & pNPB & $510 \pm 30$ & $0.17 \pm 0.03$ & $3000 \pm 600$ \\
BChE $\Omega$ Loop & pNPA & $185 \pm 6$ & $1.6 \pm 0.1$ & $116 \pm 8$ \\
Mutant with & & & & \\
A107H & & & &
\end{tabular}

pNPA (pNP-acetate) and pNPB (pNP-butyrate) assays were run in $50 \mathrm{mM}$ HEPES $\mathrm{pH} 7.0,150 \mathrm{mM} \mathrm{NaCl}, 22 \pm 3^{\circ} \mathrm{C}$. All enzymes had the N-terminal His-tag.
(Table 3). A400 was predicted to be near the choline group from structural overlays. The A107H/A400D variant had a 2fold increase in the $k_{\text {cat }} / K_{\mathrm{m}}$ for benzoylthiocholine and 9-fold increase for butyrylthiocholine when compared to $\mathrm{A} 107 \mathrm{H}$; however, the $K_{\mathrm{m}}$ values for all of the variants were $>1 \mathrm{mM}$, indicating that the pNBE variants could only weakly bind cationic substrates.

\section{OPTIMIZATION OF THE PRIMARY ASSAY USED FOR SCREENING THE DE LIBRARY}

To develop a micro-scale assay for reactivation, (His) ${ }_{6}$-tagged enzymes were bound to nickel-coated 96-well plates. To maintain near physiological conditions, the $\mathrm{pH}$ was kept at 7.6; measurement at a sub-optimal $\mathrm{pH}$ also allowed for a longer time period to carry out the subsequent steps. Two wells were coated with enzyme $(\leq 0.025 \mathrm{U}$ per well) for each variant to measure the activity of the uninhibited and inhibited enzyme. The enzyme was inhibited on the plate, and excess enzyme and inhibitor were removed. The plates were then washed with buffer. Rates of reactivation were comparable after one, two, or four washes. For the plate assay, four washes were done to ensure removal of the OPAA. After washing away excess inhibitor and unbound enzyme, the enzyme was eluted from the plate with $50 \mathrm{mM}$ EDTA. Imidazole was avoided because it readily reacted with the ester substrates (Bruice and Schmir, 1956). Aliquots were removed and assayed over time. The rate constant for reactivation for $\mathrm{A} 107 \mathrm{H}$ using the microscale assay $\left(k_{\mathrm{r}}^{2 \text { washes }}=0.22 \pm 0.08 \mathrm{~h}^{-1} ; k_{\mathrm{r}}^{4 \text { washes }}=\right.$ $0.3 \pm 0.2 \mathrm{~h}^{-1}$ ) was comparable with that determined using a gel

Table 3 | Steady state kinetic parameters for selected pNBE variants of the DE library.

\begin{tabular}{|c|c|c|c|c|c|c|}
\hline $\begin{array}{l}\text { Substrate } \\
\text { Enzyme }\end{array}$ & \multicolumn{3}{|c|}{ Benzoylthiocholine $^{a}$} & \multicolumn{3}{|c|}{ Butyrylthiocholine $^{\text {b }}$} \\
\hline $\mathrm{A} 107 \mathrm{H}$ & $13 \pm 1$ & $0.6 \pm 0.2$ & $22 \pm 7$ & $35 \pm 8$ & $17 \pm 5$ & $2.0 \pm 0.9$ \\
\hline A107H $\Omega$ Loop & $8 \pm 1$ & $0.9 \pm 0.3$ & $9 \pm 3$ & $10.4 \pm 0.9$ & $8.0 \pm 0.7$ & $1.3 \pm 0.2$ \\
\hline A107K & $570 \pm 50$ & $1.4 \pm 0.2$ & $410 \pm 70$ & $>20$ & $>8^{\mathrm{C}}$ & - \\
\hline A107S & $39 \pm 9$ & $1.4 \pm 0.6$ & $30 \pm 10$ & $780 \pm 30$ & $14.4 \pm 0.7$ & $54 \pm 3$ \\
\hline A107T & $36 \pm 3$ & $0.6 \pm 0.2$ & $60 \pm 20$ & $240 \pm 30$ & $11 \pm 2$ & $22 \pm 5$ \\
\hline A107V & $38 \pm 4$ & $0.5 \pm 0.2$ & $80 \pm 30$ & $56 \pm 8$ & $8 \pm 2$ & $7 \pm 2$ \\
\hline A107Y & $21 \pm 2$ & $0.6 \pm 0.1$ & $35 \pm 8$ & $45 \pm 5$ & $6.0 \pm 0.9$ & $7 \pm 1$ \\
\hline A107H/A190G & $29 \pm 4$ & $0.9 \pm 0.3$ & $30 \pm 10$ & $50 \pm 30$ & $11 \pm 7$ & $5 \pm 4$ \\
\hline A107H/A400D & $80 \pm 10$ & $2.1 \pm 0.6$ & $40 \pm 10$ & $190 \pm 60$ & $11 \pm 5$ & $18 \pm 9$ \\
\hline A107H/A190S/A400S & $6.4 \pm 0.9$ & $0.8 \pm 0.2$ & $9 \pm 3$ & $115 \pm 14$ & $9 \pm 1$ & $13 \pm 3$ \\
\hline
\end{tabular}

Benzoylthiocholine and butyrylthiocholine were used as substrates. Specific activities of the other variants are shown graphically in the Supplemental Information. a Benzoylthiocholine has limited solubility in DMSO, the highest substrate concentration tested was $2.5 \mathrm{mM}$.

${ }^{b}$ Butyrylthiocholine was also a poor substrate of pNBE, and $K_{m}$ values were in the mid-millimolar range. Saturation was not achieved at the highest substrate concentration tested $(8 \mathrm{mM})$. $K_{m}$ values were extrapolated from double reciprocal plots.

${ }^{c}$ Saturation was not achieved at $[S]=8 \mathrm{mM}$, and the plot of velocity vs. [S] was linear. Extrapolated $K_{m}$ 's exceeded $40 \mathrm{mM}$. 



FIGURE 3 | Reactivation data from the primary assay using a 96-well His-Select ${ }^{\circledR}$ plate. Aliquots of enzyme were removed once at each time point and assayed for CE activity using pNP-butyrate. Enzymes were reactivated in $50 \mathrm{mM}$ Tris $\mathrm{pH} 7.6,150 \mathrm{mM} \mathrm{NaCl}$. Reactivation rates measured using the assay for (A) the A107H/A190C (E10) variant, (B) the WT pNBE, and (C) the $\mathrm{A} 107 \mathrm{H}$ variant. (D) Example of reactivation rates using single point measurements for selected variants at different time points using the 96-well plate assay. Some variants showed full reactivation by the first time point while others progressively reactivated over longer time periods. (E) Reactivation rates measured for the $\mathrm{A} 107 \mathrm{H}$ variant using the 96-well plate assay after one (o) or two (•) washes to remove the inhibitor, Paraoxon. The reactivation of the WT enzyme is also shown after one $(\mathbf{\Lambda})$ or two $(\Delta)$ washes for comparison. Rates were measured in $50 \mathrm{mM}$ Tris pH 7.6, $150 \mathrm{mM} \mathrm{NaCl}$ at $37^{\circ} \mathrm{C}$. filtration column $\left(k_{\mathrm{r}}=0.53 \pm 0.09 \mathrm{~h}^{-1}\right)$ at the same $\mathrm{pH}$ and temperature. Data collected using the microscale assay and 2 washes are shown in Figure 3. The DE library was screened one to two times with the various OP. From the first round, 26 of the 95 variants were more carefully examined with large scale preps and kinetic experiments. Error in the values of $k_{\mathrm{r}}$ was higher using data collected from the microscale assay, suggesting that it is better suited for large-scale screening than for precise determination of kinetic parameters.

For slow and moderate rates of reactivation the microscale assay was useful as a primary assay for the exploration of OP inhibitors and reaction conditions (Figure 3D). The microscale assay helped identify the variants which could reactivate faster than the single variant, A107H. The vast majority of the variants did not show significant enhancements in OPAAH activity using either the discontinuous assay or a continuous assay with paraoxon; these results are consistent with other applications of DE (Dalby, 2003; Goldsmith and Tawfik, 2013). Using the OPAA activity of $\mathrm{A} 107 \mathrm{H}$ as a screening threshold, approximately $3 \%$ of the library was advanced for further testing.

The half time of reactivation for pNBE A107H was $t_{1 / 2}=$ $78 \mathrm{~min}$. Thus, observation of full reactivation at $\sim 20 \mathrm{~min}$ indicated that the $k_{\mathrm{r}}$ was $\geq 1.9 \mathrm{~h}^{-1}$ or $\geq 4$-fold faster than the $\mathrm{A} 107 \mathrm{H}$ variant. Reactivation rates for the top hits were more accurately measured using large scale preps of the enzymes and gel filtration columns.

It should be noted that the measurement of reactivation rates alone cannot identify a mechanism of OP resistance. Resistance to OP inhibition can arise from reduced binding of OP, poor stabilization of the TS, poor accommodation of the R-groups 
as the pentavalent TS forms, or increased OPAAH activity. These possibilities can only be distinguished by additional kinetic experiments. These methods are routinely used to characterize pesticide resistance mechanisms in insecticide-insensitive AChE variants (Newcomb et al., 1997; Temeyer et al., 2012; Zhang et al., 2012).

\section{VARIANTS WITH ENHANCED OPAAH ACTIVITY}

After screening the library of 95 variants for reactivation after paraoxon inhibition, three variants were found to reactivate faster than the A107H variant: A107H/A400M (H2), A107H/A190G (F2), and A107H/A190C (E10). The A107H/A190C double variant was found to have the greatest rate enhancement. Relative to the WT pNBE $\left(k_{\mathrm{r}}^{\text {Paraoxon }}=0.03 \pm 0.01 \mathrm{~h}^{-1}\right)$, the rate constant for reactivation following paraoxon inhibition was 18 -fold higher for the A107H variant $\left(k_{\mathrm{r}}^{\text {Paraoxon }}=0.53 \pm 0.09 \mathrm{~h}^{-1}\right)$, and 50 -fold higher for the A107H/A190C double variant $\left(k_{\mathrm{r}}=1.5 \pm 0.2 \mathrm{~h}^{-1}\right)$ (Table 4). Consistent with the aliesterase hypothesis (Oppenoorth and van Asperen, 1960), the turnover number for pNBE-catalyzed

\section{Table 4 | Rates of reactivation after ethyl paraoxon inhibition measured for the $D E$ variants at $37^{\circ} \mathrm{C}$ in $50 \mathrm{mM}$ Tris pH 7.6, $150 \mathrm{mM}$ $\mathrm{NaCl}, 2$ mM BME.}

\begin{tabular}{|c|c|c|c|}
\hline Enzyme & CLONE & $k_{\text {reactivation }}(1 / \mathrm{h})$ & \% Reactivation \\
\hline A107 & D3 & $0.03 \pm 0.01$ & $110 \pm 10$ \\
\hline $\mathrm{A} 107 \mathrm{C}$ & D4 & $0.15 \pm 0.03$ & $40 \pm 3$ \\
\hline A107D & D5 & $0.31 \pm 0.02$ & $90 \pm 2$ \\
\hline A107E & D6 & $0.048 \pm 0.006$ & $46 \pm 4$ \\
\hline A107F & D7 & $0.023 \pm 0.004$ & $130 \pm 10$ \\
\hline $\mathrm{A} 107 \mathrm{G}$ & D8 & $0.0114 \pm 0.0009$ & $70 \pm 4$ \\
\hline $\mathrm{A} 107 \mathrm{H}$ & - & $0.53 \pm 0.09$ & $102 \pm 5$ \\
\hline A107I & D9 & $0.013 \pm 0.004$ & $70 \pm 4$ \\
\hline A107K & D10 & $0.04 \pm 0.02$ & $25 \pm 6$ \\
\hline A107L & D11 & $0.030 \pm 0.005$ & $25 \pm 2$ \\
\hline A107M & D12 & $0.06 \pm 0.03$ & $90 \pm 10$ \\
\hline $\mathrm{A} 107 \mathrm{~N}$ & E1 & $0.04 \pm 0.01$ & $60 \pm 10$ \\
\hline A1070 & E3 & $0.05 \pm 0.02$ & $110 \pm 10$ \\
\hline A107R & E4 & $0.14 \pm 0.03$ & $27 \pm 2$ \\
\hline A107S & E5 & $0.03 \pm 0.01$ & $100 \pm 10$ \\
\hline A107T & E6 & $0.034 \pm 0.006$ & $40 \pm 5$ \\
\hline A107V & E7 & $0.22 \pm 0.03$ & $28 \pm 1$ \\
\hline A107Y & E9 & $0.012 \pm 0.003$ & $7 \pm 1$ \\
\hline A107H/A190C & E10 & $1.5 \pm 0.2^{\mathrm{a}}$ & $62 \pm 3$ \\
\hline A107H/A190V & $\mathrm{G} 2$ & $0.4 \pm 0.1$ & $73 \pm 9$ \\
\hline A107H/A190G & F2 & $0.7 \pm 0.3$ & $90 \pm 10$ \\
\hline $\mathrm{A} 107 \mathrm{H} / \mathrm{A} 190 \mathrm{H}$ & F3 & $0.10 \pm 0.02$ & $66 \pm 8$ \\
\hline A107H/A190M & F7 & $0.3 \pm 0.2$ & $17 \pm 5$ \\
\hline $\mathrm{A} 107 \mathrm{H} / \mathrm{A} 400 \mathrm{~W}$ & $\mathrm{H} 10$ & $0.4 \pm 0.2$ & $130 \pm 50$ \\
\hline $\mathrm{A} 107 \mathrm{H} / \mathrm{A} 400 \mathrm{M}$ & $\mathrm{H} 2$ & $1.0 \pm 0.2$ & $97 \pm 7$ \\
\hline $\mathrm{A} 107 \mathrm{H} / \mathrm{A} 400 \mathrm{~V}$ & $\mathrm{H} 9$ & $0.6 \pm 0.1$ & $130 \pm 20$ \\
\hline A107H/A190C/A400T & A8 & $0.43 \pm 0.07$ & $92 \pm 7$ \\
\hline A107H/A190C/A400T & A8 & $1.0 \pm 0.1^{\mathrm{a}}$ & $75 \pm 5$ \\
\hline A107H/A190C/A400M & $\mathrm{C} 4$ & $1.0 \pm 0.1^{a}$ & $75 \pm 5$ \\
\hline
\end{tabular}

${ }^{a}$ Enzymes were heated at $37^{\circ} \mathrm{C}$ prior to reactivation. hydrolysis of the ester substrates, pNPA or pNPB, progressively decreased as OP-hydrolase activity increased (Table 2). Thus, as OP-hydrolase activity is evolved to accommodate a pentavalent TS of an OP, the carboxylesterase activity and stabilization of a tetrahedral transition state is lost (Oppenoorth and van Asperen, 1960). For soman, the largest rate enhancements were observed (Table 5). Somanase activity was not observed in the G117H BChE single mutant (Millard et al., 1998) until a second mutation was added (G117H/E197Q). In pNBE, the $\mathrm{A} 107 \mathrm{H}$ mutation (equivalent to $\mathrm{G} 117 \mathrm{H}$ in $\mathrm{BChE}$ ) enhanced the rate of spontaneous reactivation after soman inhibition, but an additional rate enhancement was achieved with the A107H/A190C variant. The $k_{\mathrm{r}}$ for $\mathrm{A} 107 \mathrm{H}\left(k_{\mathrm{r}}^{\text {Soman }}=0.7 \pm 0.1 \mathrm{~h}^{-1}\right)$ was 700 -fold above WT $\left(k_{\mathrm{r}}^{\text {Soman }}=0.001 \pm 0.004 \mathrm{~h}^{-1}\right)$ and 4000 -fold higher for the $\mathrm{A} 107 \mathrm{H} / \mathrm{A} 190 \mathrm{C}$ variant $\left(k_{\mathrm{r}}^{\text {Soman }}=4 \pm 1 \mathrm{~h}^{-1}\right)$. The trends were similar to those observed with paraoxon (Table 4). A190 in pNBE is also at a different location than E197 in BChE, and rate enhancements in OP-hydrolase activity have not been reported from mutations at this site (Figure S1D).

The variant which displayed the greatest rate enhancements in OP-hydrolase activity, A107H/A190C, exhibited unexpected kinetic complexity consistent with a slow conformational change in the enzyme. Pre-incubation of the purified A107H/A190C enzyme at $37^{\circ} \mathrm{C}$ in the absence of any substrate or inhibitor caused a subsequent time-dependent increase in $\mathrm{V}_{\max }$ for CE activity and the reactivation rate constants for selected OPAA (Figure S3). Maximal CE activity could be achieved by pre-incubating the enzyme at $37^{\circ} \mathrm{C}$ in $50 \mathrm{mM}$ Tris $\mathrm{pH} 7.6,150 \mathrm{mM} \mathrm{NaCl}, 2 \mathrm{mM}$ $\mathrm{BME}$ for $\geq 2 \mathrm{~h}$. Likewise, pre-equilibrating A107H/A190C to $37^{\circ} \mathrm{C}$ for $\geq 2 \mathrm{~h}$ doubled the apparent dephosphonylation rate constant following paraoxon or soman inhibition (Tables 4,5 ). The dephosphorylation rate constant following DFP inhibition was not similarly affected. The DFP-inhibited A107H/A190C variant reactivated 5-fold more slowly than did A107H (Table 6), and no further increases could be gained by heating the enzyme. We also tested the triple mutant, A107H/A190C/A400M, for temperature-dependent hysteresis but found no significant effect on reactivation (Table 5 ).

Several mutations at the A190 and A400 positions were compatible with $\mathrm{A} 107 \mathrm{H}$. The backbone $\mathrm{NH}$ groups of A107 and A190 form part of the oxyanion hole. Changes in the polarity of these $\mathrm{NH}$ groups have been proposed to enhance OPAAH activity

Table 5 | Rates of reactivation after inhibition with soman.

\begin{tabular}{lccc}
\hline Enzyme & $\boldsymbol{k}_{\text {reactivation }}(\mathbf{1} / \mathbf{h})$ & \% Reactivated & $\begin{array}{c}\text { Fold } \\
\text { increase }\end{array}$ \\
\hline WT & $0.001 \pm 0.004$ & $<4 \%$ after $5.5 \mathrm{~h}$ & - \\
$\mathrm{A} 107 \mathrm{H}$ & $0.7 \pm 0.1$ & $106 \pm 8$ & 700 \\
$\mathrm{~A} 107 \mathrm{H} / \mathrm{A} 190 \mathrm{C}^{\mathrm{a}}$ & $1.8 \pm 0.2$ & $44 \pm 5$ & 1800 \\
$\mathrm{~A} 107 \mathrm{H} / \mathrm{A} 190 \mathrm{C}^{\mathrm{b}}$ & $4 \pm 1$ & $43 \pm 6$ & 4000 \\
$\mathrm{~A} 107 \mathrm{H} / \mathrm{A} 190 \mathrm{C} / \mathrm{A} 400 \mathrm{M}^{\mathrm{a}}$ & $0.7 \pm 0.2$ & $20 \pm 2$ & 700 \\
A107H/A190C/A400M & $1.2 \pm 0.5$ & $17 \pm 2$ & 1200 \\
\hline
\end{tabular}

${ }^{a}$ Without heating prior to inhibition.

${ }^{b}$ With $2 \mathrm{~h}$ of heating at $37^{\circ} \mathrm{C}$ prior to reactivation at $37^{\circ} \mathrm{C}$. 
(Yao et al., 2012). Hydrophobic mutations A400M and A400V within the loop slightly enhanced the rate of reactivation. The A107H/A400M (H2) and A107H/A190G (F2) double mutants showed the second largest enhancements, but additive effects were not observed in the A107H/A190C/A400M variant or any other triple mutant.

Having constructed a DE library with all 20 amino acids at position A107, we also determined if other residues at this position were more effective than histidine in catalyzing reactivation. In addition to $\mathrm{A} 107 \mathrm{H}$, the variants $\mathrm{A} 107 \mathrm{C}, \mathrm{A} 107 \mathrm{D}$, and $\mathrm{A} 107 \mathrm{~V}$ showed apparent reactivation rate enhancements for selected OPAA compared with WT pNBE. Of this group, however, only A107H and A107D fully reactivated after inhibition by paraoxon (Table 4). This result is similar to what was reported by Schopfer et al. (2004). Schopfer observed OP hydrolase activity in G117D, $\mathrm{G} 117 \mathrm{E}$, and $\mathrm{L} 286 \mathrm{H}$ variants of BChE.

\section{TRANSFER OF MUTATIONS ONTO hCE1}

The spontaneous reactivation rate constant for WT hCE1 inhibited with paraoxon was low (Table 7). This is consistent with reports that WT hCE1 can be irreversibly inhibited by stereoisomers of soman or cyclosarin (Hemmert et al., 2010). The mutation equivalent to $\mathrm{G} 117 \mathrm{H}$ in $\mathrm{BChE}$ was made in hCE1 $(\mathrm{G} 143 \mathrm{H})$, but did not enhance or confer OPAAH activity (Table 7). The hCE1 loop residues 302-320 (equivalent to 276290 in BChE) that form the acyl pocket differ significantly among hCE1, pNBE, and BChE. In snake AChE, the single G122H mutation (homologous to BChE G117H) did not increase OPAAH activity; only introduction of two additional mutations (G122H/Y124Q/S125T) permitted engineering of limited spontaneous reactivation following slow inhibition with selected OPAA (Poyot et al., 2006). Thus, while pNBE is more similar to hCE1

Table 6 | Rates of reactivation at pH 7.6 after inhibition with DFP.

\begin{tabular}{lcc}
\hline Enzyme & $\boldsymbol{k}_{\text {reactivation }}(\mathbf{1 / h})$ & \% Reactivated \\
\hline A107H & $0.6 \pm 0.1$ & $110 \pm 10$ \\
A107H/A190C & $0.13 \pm 0.08$ & $150 \pm 40$ \\
A107H/A190C & $0.17 \pm 0.01$ & $69 \pm 2$ \\
A107H/A190G & $0.63 \pm 0.06$ & $108 \pm 3$ \\
\hline
\end{tabular}

${ }^{a}$ Heated for $3 \mathrm{~h}$ at $37^{\circ} \mathrm{C}$ prior to reactivation.

Table 7 | Rates of reactivation of hCE1 after inhibition with paraoxon.

\begin{tabular}{lccc}
\hline Enzyme & $\mathbf{p H}$ & $\boldsymbol{k}_{\text {reactivation }}(\mathbf{1} / \mathbf{h})$ & \% Reactivated \\
\hline hCE1 WT & 7.0 & $0.078 \pm 0.006$ & $92 \pm 3$ \\
& 7.6 & $0.102 \pm 0.006$ & $98 \pm 3$ \\
\hline hCE1 G143H & 7.0 & $0.025 \pm 0.008$ & $45 \pm 8$ \\
& 7.6 & $0.03 \pm 0.03$ & $15 \pm 2$ \\
\hline hCE1 G143H/A222C & 7.0 & $0.007 \pm 0.003$ & $120 \pm 60$ \\
& 7.6 & $0.009 \pm 0.007$ & $11 \pm 8$
\end{tabular}

in terms of substrate specificity, the utility of $\mathrm{pNBE}$ as a surrogate scaffold still remains to be explored.

\section{INHIBITION BY PARAOXON}

Reliable measurement of $\mathrm{IC}_{50}$ or $K_{\mathrm{i}}$ values requires enzyme concentrations below the $K_{\mathrm{i}}$. For enzymes with $\mathrm{IC}_{50}$ values in the $\mathrm{nM}$ range, only upper limits can typically be measured. The minimum amount of enzyme needed to obtain a signal/noise ratio $>2$ was $0.5 \mathrm{nM}$ of enzyme. The observed $\mathrm{IC}_{50}(0.37 \mathrm{nM})$ for paraoxon was almost equal with the enzyme concentration $(0.5 \mathrm{nM})$, suggesting that the $\mathrm{IC}_{50} \leq 0.5 \mathrm{nM}$. Thus, $\mathrm{pNBE}$ is an effective scavenger of paraoxon at low $\mathrm{nM}$ concentrations. Similar values have been reported for AChE with soman and sarin $\left[\mathrm{IC}_{50}^{\text {soman }}=0.88\right.$ $2.53 \mathrm{nM}, \mathrm{IC}_{50}^{\mathrm{sarin}}=3.27-6.15 \mathrm{nM}$ (Fawcett et al., 2009)].

\section{INHIBITION BY ECHOTHIOPHATE}

pNBE and hCE1 share the cholinesterase fold, but lack cholinesterase activity. To determine if V-type inhibitors with choline-like leaving groups could be accommodated by variants, we screened the library with echothiophate and looked for irreversible inhibition. Through one mutation, A107S, we were able to achieve a 50 -fold increase in the rate of inhibition. However, for the pNBE variants tested, the $K_{p}$ values remained high (millimolar range) compared with those of natural cholinesterases (Table 8).

\section{DISCUSSION}

Arnold and colleagues have shown that B. subtilis pNBE can be modified to achieve increased thermostability, broadened substrate specificity, or improved reactivity in organic solvents using DE (Giver et al., 1998; Spiller et al., 1999; Brustad and Arnold, 2011). DE is a large scale site-directed mutagenesis experiment where selected residues are mutated to all 20 amino acids, or random mutations are introduced to alter catalytic activity and/or substrate specificity (Brustad and Arnold, 2011). This process generates 20 different enzymes for each selected site or thousands of variants with mutations at random sites (reviewed by Goldsmith and Tawfik, 2013); screening thousands of mutants is typically impractical. Several approaches are available for

Table 8 | Inhibition by echothiophate.

\begin{tabular}{lccc}
\hline Enzyme & $\boldsymbol{k}_{\mathbf{2}}(\mathbf{1} / \mathbf{m i n})$ & $\boldsymbol{K}_{\boldsymbol{p}}(\mathbf{m M})$ & $\boldsymbol{k}_{\mathbf{2}} / \boldsymbol{K}_{\boldsymbol{p}}\left(\mathbf{1} / \mathbf{m i n} \mathbf{m}^{*} \mathbf{m}\right)$ \\
\hline A107H & $0.013 \pm 0.005$ & $9 \pm 4$ & $0.0014 \pm 0.0008$ \\
A107K & $0.014 \pm 0.005$ & $10 \pm 4$ & $0.0014 \pm 0.0008$ \\
A107S & $0.7 \pm 0.4$ & $10 \pm 7$ & $0.07 \pm 0.06$ \\
A107T & $0.06 \pm 0.05$ & $11 \pm 8$ & $0.006 \pm 0.006$ \\
A107R & $0.02 \pm 0.04$ & $>5$ & $0.00045 \pm 0.00009^{a}$ \\
A107Q & $0.079 \pm 0.008$ & $3 \pm 1$ & $0.026 \pm 0.009$ \\
A107V & $0.10 \pm 0.02$ & $20 \pm 4$ & $0.005 \pm 0.001$ \\
A107Y & $0.06 \pm 0.04$ & $20 \pm 1$ & $0.004 \pm 0.004$ \\
\hline
\end{tabular}

Rates were measured using $1 \times$ Sorensen's buffer $\mathrm{pH} 7.4$ at room temperature $\left(22 \pm 2^{\circ} \mathrm{C}\right)$.

anhibition was observed; however, the intercept could not be determined accurately from a distant extrapolation (very weak binding). 
generating large libraries of mutants, but there are far fewer validated methods for selecting mutants with the desired activity. Here we constructed a "focused" DE library, utilized a bacterial homolog as a surrogate scaffold, and restricted the mutations to residues within a $7 \AA$ radius of the nucleophilic serine. While pNBE, AChE, BChE, and hCE1 share a common fold (Figure S1), it is known that the single mutation analogous to $\mathrm{G} 117 \mathrm{H}$ in $\mathrm{BChE}$ does not confer OP-hydrolase activity in AChE (Ordentlich et al., 1998; Poyot et al., 2006). Based upon substrate specificities, we show that $\mathrm{pNBE}$ and hCE1 are similar (this paper). However, when we examined the $\mathrm{A} 107 \mathrm{H}$ variant of $\mathrm{pNBE}$ and the $\mathrm{G} 123 \mathrm{H}$ variant of hCE1, we found that the histidine substitution only conferred OP-hydrolase activity in pNBE. Our preliminary results demonstrate that $\mathrm{pNBE}$ is a suitable prokaryotic scaffold for engineering improved reactivity with a range of OPAA inhibitors including soman, but that it is sufficiently different from hCE1 that additional mutations would be required.

While a significant enhancement in the rate of reactivation after soman inhibition was achieved $\left(10^{3}\right.$-fold increase, Table 5) the pNBE A107H variant did not achieve the same rates of reactivation as the $\mathrm{BChE} \mathrm{G} 117 \mathrm{H}$ variant $\left[k_{\mathrm{r}}^{\mathrm{BChE}-S o m a n}=6000 \pm 600\right.$ $1 / \mathrm{min}$ (Millard et al., 1998) vs. $k_{\mathrm{r}}^{\mathrm{pNBE}-\mathrm{E} 10-\text { Soman }}=0.07 \pm 0.02$ $1 / \mathrm{min}]$. This may in part be due to the more open active site of pNBE (Figure 2A) vs. the tunnel-like gorge of AChE and BChE.

One other complication was a slow time- and temperaturedependent change in activity in the variant which had the largest enhancement $\left(10^{3}\right.$-fold) in OP-hydrolase activity. Various forms of hysteresis in AChE and BChE have been observed kinetically (Masson et al., 2005; Badiou et al., 2008; Masson and Lockridge, 2010; Lushchekina et al., 2014), and possibly structurally (Nachon et al., 2011). Non-linear kinetic curves for BChE G117H also were observed with selected substrates (Millard et al., 1995b). Hysteresis affecting CE activity of both BChE and AChE (Masson et al., 2005; Badiou et al., 2008; Masson and Lockridge, 2010; Lushchekina et al., 2014) and OP-hydrolase activity (Masson, 2012) has been reported and has been attributed to the flipping of the His of the catalytic triad. A pronounced lag phase ( $3 \mathrm{~min}$ ) was observed in the BChE A328C mutant at $25^{\circ} \mathrm{C}$ (Masson, 2012); the side chain of this residue is near His- 438 of the triad $(\sim 4.5 \AA)$. In pNBE the mechanism of hysteresis may or may not be the same since the A190 side chain is behind the oxyanion hole residues and is relatively distant from His-399 (>7 $\AA$ ) (Figure S1). If the His of the catalytic triad is involved, however, the methionine residue in the A107H/A190C/A400M variant which did not display hysteresis may stabilize a particular rotamer of His-399. This mutant displayed a lower percentage of reactivated enzyme after soman inhibition when compared with A107H/A190C (Table 5) suggesting that conformational changes may be important in the mechanism of reactivation.

Hysteresis is rarely considered during DE screening, but can limit achievable rates of hydrolysis. It also complicates the interpretation of site-directed mutagenesis and structural studies since the crystallized structure may (or may not) represent the catalytically competent state. We observed kinetic complexity in the A107H/A190C pNBE variant that affected both esterase and OPhydrolase activity. This suggests the involvement of a residue(s) which plays a role in both esterase and OP-hydrolase activity.

\section{INTRODUCTION OF OPAAH ACTIVITY TO pNBE}

The overarching goal of developing a nerve agent bioscavenger is to find or engineer a biocompatible enzyme that rapidly binds and hydrolyzes a broad range of neutral (G-type agents) and positively charged (V-type) OPAA under physiological conditions where the inhibitor is present at sub-micromolar concentrations. Cholinesterases react rapidly with all known OPAA nerve agents, but effectively remain inhibited irreversibly due to the stability of the OPAA-enzyme complex.

Introducing a single His $(\mathrm{G} 117 \mathrm{H})$ into human BChE converts the enzyme into a modest OPAAH by increasing the spontaneous reactivation rate constant while retaining reactivity with a broad range of inhibitors (Millard et al., 1995a; Lockridge et al., 1997). Follow-on attempts to incorporate His-117 into human or Bungarus fasciatus AChE were relatively unsuccessful (Poyot et al., 2006). pNBE is the second esterase to show an enhancement in OPAAH activity by introduction of a single His (A107H corresponds to $\mathrm{G} 117 \mathrm{H}$ ) and is significantly more amenable to E. coli expression.

Lockridge and colleagues rationally designed and tested more than 60 double or triple mutants of human BChE based upon the initial success with His-117, but none of these variants improved upon the OPAAH activity of G117H (Lockridge et al., 1997; Schopfer et al., 2004). We find a similar result using DE with pNBE. Although enhancements of spontaneous reactivation compared to WT were measured following paraoxon inhibition for pNBE A107D, A107V or A107C, the histidine mutant $(\mathrm{A} 107 \mathrm{H})$ showed the fastest and most complete dephosphorylation (Table 4). pNBE A107D is homologous with the blowfly CE G137D mutant that was isolated by screening OP-resistant populations of Lucilia cuprina for naturally occurring variants of G117H (Newcomb et al., 1997). A107D showed enhanced spontaneous reactivation compared with $\mathrm{WT}$, but the turnover rates with paraoxon were slower than those of either pNBE A107H or the blowfly CE G137D (cf. Table 4 and Kirby et al., 2013).

Cholinesterases and carboxylesterases must stabilize a tetrahedral transition state to catalyze carboxyl ester hydrolysis, whereas the transition state of an organophosphate is generally a pentavalent trigonal bipyramid. Consequently, all attempts to engineer OPAAH activity into these enzymes must accept a significant risk of concomitant loss of natural esterase activity. Oppenoorth's "aliesterase hypothesis" was based upon this observed interchange in substrate specificities (Oppenoorth and van Asperen, 1960). Our results with pNBE generally confirmed this hypothesis with the trend showing that mutations increasing OPAAH activity also showed decreasing carboxylesterase activity (Tables 1-7).

The pNBE A107H/A190C variant showed a slow time- and temperature-dependent increase in $\mathrm{CE}$ activity and the rate of spontaneous reactivation following inhibition with paraoxon or soman (Figure S3; Tables 4, 5), but not with DFP (Table 6). DFP, unlike soman or paraoxon, has two bulky R-groups (Figure 1) which may restrict the pNBE active site from reaching the temperature-induced conformational change required for the higher level of activity. It has been shown that the DFP reaction significantly alters the conformation of the acyl pocket loop of AChE (Millard et al., 1999; Hornberg et al., 2007). The corresponding loop of $\mathrm{pNBE}$ is predicted to be nearby His-107 
(Figure 2). Thus, the catalytically competent conformer of the histidine or hydrolytic water molecule may be affected by conformational changes in the loop. The simultaneous mutation of two residues (A107/A190) may permit subtle, local movements of the NH groups of the oxyanion hole that are sufficient to enhance catalysis (Yao et al., 2012). Alternatively, the double mutant may have more distal effects to structure the disordered loops of WT pNBE. It was shown previously that mutations which thermally stabilize the enzyme also increase the optimal temperature for pNBE carboxylesterase activity (Giver et al., 1998); the omega loop of the thermal stable pNBE variant (PDB 1C7I) is structured (Spiller et al., 1999).

\section{IMPORTANCE OF THE OXYANION HOLE}

Much of the catalytic power of serine hydrolases derives from the oxyanion hole (Bryan et al., 1986; Zhang et al., 2002; Warshel, 2003; Bobofchak et al., 2005), and we hypothesize that the same is true for engineered OPAAH activity. Millard and colleagues originally proposed the spontaneous reactivation of $\mathrm{G} 117 \mathrm{H}$ was acid catalyzed and might involve a direct $\mathrm{H}$-bond from the imidazolium to the phosphonyl (double bond) oxygen to stabilize the dephosphylation transition state, or an indirect steric effect that distorts the preformed electrostatic environment of the oxyanion hole and thereby permits the catalytic triad His-438 to catalyze reactivation (Millard et al., 1995a, 1998). Related and alternative mechanisms subsequently have been proposed (Lockridge et al., 1997; Newcomb et al., 1997; Albaret et al., 1998; Schopfer et al., 2004; Poyot et al., 2006; Nachon et al., 2011; Yao et al., 2012), supported, or refuted based upon analogy with followon His-117 mutations to related enzymes, molecular modeling studies (Amitay and Shurki, 2009; Yao et al., 2012) or static, medium resolution X-ray crystal structures (Masson et al., 2007); however, the actual enzyme mechanism of $\mathrm{G} 117 \mathrm{H}$ remains unresolved.

Our studies on the structurally homologous pNBE mutants may provide useful data for ongoing efforts to elucidate the G117H mechanism. First, like G117H, placing a histidine residue at the homologous $\mathrm{A} 107 \mathrm{H}$ position in the oxyanion hole enhanced OPAAH activity with a range of inhibitors (Tables 4, 5). Second, OPAAH activity increased as the $\mathrm{pH}$ decreased from 7.6 to 7.0 , consistent with a mechanism that is acid-catalyzed. Third, the A190C mutation further enhanced the rate of reactivation of the A107H mutation. The $\mathrm{NH}$ group of A190 forms part of the 3-point oxyanion hole, and the side chain would be expected to point away from the oxyanion. Finally, we observed a slow time- and temperature-dependent change in carboxylesterase and OPAAH activity of the A107H/A190C variant that may be consistent with a conformational change or some other reversible modification in the free enzyme which enhances the role of these residues in catalysis. Additional work is required to determine if these observations can be translated to improve human $\mathrm{BChE}$ G117H activity.

\section{INTRODUCTION OF LIMITED CHOLINESTERASE ACTIVITY}

One objective of this work was to determine if cholinesterase activity could be introduced into pNBE. The active site cavity of $\mathrm{pNBE}$ is formed by four loops that are largely disordered in the WT enzyme crystal structure, viz. residues 64-71 (unstructured) and 413-417 (unstructured) on one side of the active site, and 316-320 (unstructured) and 260-268 (structured) on the other side (Spiller et al., 1999). It appears that these flexible loops become longer, more differentiated and ordered through evolution to form the substrate specificity loops observed in the X-ray structures of AChE and BChE. One side becomes the cholinesterase "acyl pocket loop," which we have shown previously to have reversible conformational flexibility in Torpedo californica ( $T c$ ) AChE when binding selected OPAA (Millard et al., 1999; Hornberg et al., 2007). The other side develops the so-called $\Omega$-loop carrying Trp-84 (TcAChE numbering; Trp-82 in BChE), a residue that complements trimethyl or choline-like substrate leaving groups.

Residues corresponding to the cholinesterase $\Omega$-loop are disordered in the structure of WT pNBE [PDB 1QE3 (Spiller et al., 1999)]. Both pNBE and hCE1 lack the critical Trp- 84 side chain (Figure 2E) (Satoh and Hosokawa, 1995; Imai et al., 2006), and this probably explains why these enzymes are relatively poor at binding cationic substrates (e.g., ATCh and BTCh; Table 3) or echothiophate (Table 8). Our initial experiment to insert the entire $\Omega$-loop into pNBE is a first step in evolving the bacterial enzyme toward a cholinesterase. The loop was accepted by the pNBE fold and had little or no effect on the reactivity of the enzyme with neutral substrates or inhibitor; however it also did not result in detectable activity with positively charged substrates (Table 3). While this rational design attempt with the $\Omega$-loop failed to increase cholinesterase activity, the focused DE exploration succeeded in finding A $107 \mathrm{~K}$ which demonstrated an almost 10 -fold increase in its specificity constant for benzyolthiocholine compared with WT.

\section{COMPARISON OF pNBE AND hCE1}

Human carboxylesterase has been proposed as an alternative or adjunct bioscavenger to the cholinesterases because hCE1 is abundant in human liver, binds and hydrolyzes some neutral OPAA nerve agents, and does not undergo significant aging after inhibition with the most deadly OPAA nerve agent, soman (Hemmert et al., 2010). However, the primary limitation to using hCE as a nerve agent bioscavenger is the slow reaction rates with positively charged OPAA. In our study, cholinesterase activity could be introduced into pNBE by the A107K mutation, but the amount was still several orders of magnitude below that of cholinesterases and the mutation had no effect on the bimolecular rate constant for inhibition by a cationic OPAA (echothiophate; Table 8). More importantly, the G143H mutation did not confer OPAAH activity in hCE1 (Table 7).

In summary, along with its primary sequence and structural homology to the cholinesterases and the shared use of a rare Glu residue instead of Asp in the catalytic triad, we have shown that $B$. subtilis pNBE can accommodate the cholinesterase $\Omega$-loop without detriment to protein folding or endogenous esterase activity. We have also identified an unexpected point mutation $(\mathrm{A} 107 \mathrm{~K})$ that significantly increases turnover of a positively charged substrate. Moreover, like BChE but not $\mathrm{AChE}$ or hCE1, the pNBE structure accepts substitutions (A107H or A107H/A190C) corresponding with G117H that confer 
significant OPAAH activity, thereby expanding the enzyme's natural substrate specificity to include phosphoric and phosphonic acid esters. Taken together, these results suggest to us that pNBE is an excellent prokaryotic scaffold for follow-on DE studies, as well as other methods like incorporation of unnatural amino acids, that can inform new pathways for continued engineering of useful cholinesterase and/or OPAAH activity within the $\alpha / \beta$-hydrolase superfamily.

\section{ACKNOWLEDGMENTS}

We thank SSG Derrick Robinson for assistance with steady state kinetic assays and Dr. Michael S. Lee for helpful discussions. Dr. Phillip Potter of St. Jude Children's Research Hospital kindly provided us with the clone for WT pNBE. This work was funded by the U.S. Defense Threat Reduction Agency JSTO award 1.D0006_08_WR_C (Charles B. Millard). The opinions or assertions contained herein belong to the authors and are not necessarily the official views of the U.S. Army, U.S. Navy, or the U.S. Department of Defense.

\section{SUPPLEMENTARY MATERIAL}

The Supplementary Material for this article can be found online at: http://www.frontiersin.org/journal/10.3389/fchem. 2014.00046/abstract

A graph of the esterase activities of the individual mutants in the DE library, evidence of reversible hysteresis, and sequence alignments of the enzymes discussed in this study are included in the Supplemental Information.

Scheme S1 | Organophosphate inhibition, spontaneous reactivation, and aging.

Figure S1 | Acylation-the first step in the catalytic cycle. (A) The serine hydrolases AChE (2ACE), BChE (1P0M), hCE1 (2HRR), and pNB-esterase (10E3) all share a common fold, but have very different substrate specificities. This is in part due to residues within the $\Omega$-loop (colored red) which form part of the choline binding pocket in AChe and BChE. The equivalent loop in pNBE is disordered in the crystal structure 10E3. (B) The acylation step and active site of pNBE. Residues of the catalytic triad are boxed. (C) The acylation step and active site of BChE. The cationic choline ester is accommodated by Glu-197 and Trp-82. Trp-82 of the $\Omega$-loop makes an important cation-pi interaction with the choline ester and $\mathrm{V}$-type agents (VX and VR) which mimic choline esters. (D) Alternate views of the Ala-190 side chain. A190 is behind the loop of the oxyanion hole residues $\mathrm{G} 106$ and $\mathrm{A} 107$.

Figure S2 | Specific activities (S.A., U/mg) for all 95 variants in the DE library using five substrates: pNPA, pNPB, benzoylthiocholine, butyrylthiocholine, and acetylthiocholine. S.A. from single point assays were measured using $5,1,2.5,2.5$, and $2.5 \mathrm{mM}$ of the substrates, respectively. In well D3 is the WT pNBesterase enzyme (where A107 is an alanine). For all other mutants the $\mathrm{A} 107 \mathrm{H}$ mutation is present in combination with the denoted mutation. For the A107X mutants (where $\mathrm{X}$ = any amino acid), only the single mutation is present. Note, the $y$-scale has been adjusted for some graphs. For variants with no visible bars, values near the spontaneous rate of hydrolysis were measured and plotted. One substrate, pNPB, was hydrolyzed at detectable levels for all of the mutants. The S.A. were needed to determine the number of Units per well to use in the microscale reactivation rate experiments described.
Steady state kinetic parameters were measured for selected variants which showed enhancements in esterase activity and are described in Tables 2, 3. Reductions in carboxylesterase activity were expected for variants which had acquired OP-hydrolase activity [Aliesterase Hypothesis (Oppenoorth and van Asperen, 1960)]. SDS-PAGE gel showing the purity of 10 variants purified using small scale preps and single columns.

Figure S3 | Effect of hysteresis on carboxylester hydrolysis. The E10 A 107 H/A190C double variant showed a 6-fold increase in its carboxylesterase activity after elution from a PD-10 column during $37^{\circ} \mathrm{C}$ incubation periods. For assays, $10 \mu \mathrm{L}$ of the enzyme was added to a $1 \mathrm{~mL}$ reaction volume, and rates were measured at R.T. This dramatic increase in activity was not observed for any other variant.

\section{Supplemental Information | Sequence alignment of the constructs} discussed. The pNBE sequence corresponds to P37967; it contains strain-specific differences from the sequence of PDB 1 OE3.

\section{REFERENCES}

Aharoni, A., Gaidukov, L., Yagur, S., Toker, L., Silman, I., and Tawfik, D. S. (2004). Directed evolution of mammalian paraoxonases PON1 and PON3 for bacterial expression and catalytic specialization. Proc. Natl. Acad. Sci. U.S.A. 101, 482-487. doi: 10.1073/pnas.2536901100

Albaret, C., Masson, P., Broomfield, C. A., El Kaim, L., and Fortier, P. L. (1998). "Mechanical aspects of the phosphotriesterase activity of human butyrylcholinesterase G117H mutant," in Structure and Function of Cholinesterases and Related Proteins, ed B. P. Doctor (New York, NY: Plenum Press), 399-405. doi: 10.1007/978-1-4899-1540-5_117

Amitay, M., and Shurki, A. (2009). The structure of G117H mutant of butyrylcholinesterase: nerve agents scavenger. Proteins 77, 370-377. doi: $10.1002 /$ prot.22442

Ashani, Y. (2000). Prospective of human butyrylcholinesterase as a detoxifying antidote and potential regulator of controlled-release. Drugs Dev. Res. 50, 298-308. doi: 10.1002/1098-2299(200007/08)50:3/4<298::AID-DDR13>3.0.CO;2-X

Badiou, A., Froment, M. T., Fournier, D., Masson, P., and Belzunces, L. P. (2008). Hysteresis of insect acetylcholinesterase. Chem. Biol. Interact. 175, 410-412. doi: 10.1016/j.cbi.2008.05.039

Bobofchak, K. M., Pineda, A. O., Mathews, F. S., and Di, C. E. (2005). Energetic and structural consequences of perturbing Gly-193 in the oxyanion hole of serine proteases. J. Biol. Chem. 280, 25644-25650. doi: 10.1074/jbc.M503499200

Bruice, T. C., and Schmir, G. L. (1956). The catalysis of the hydrolysis of pnitrophenyl acetate by imidazole and its derivatives. Arch. Biochem. Biophys. 63, 484-486. doi: 10.1016/0003-9861(56)90068-6

Brustad, E. M., and Arnold, F. H. (2011). Optimizing non-natural protein function with directed evolution. Curr. Opin. Chem. Biol. 15, 201-210. doi: 10.1016/j.cbpa.2010.11.020

Bryan, P., Pantoliano, M. W., Quill, S. G., Hsiao, H. Y., and Poulos, T. (1986). Sitedirected mutagenesis and the role of the oxyanion hole in subtilisin. Proc. Natl. Acad. Sci. U.S.A. 83, 3743-3745. doi: 10.1073/pnas.83.11.3743

Cherny, I. Greisen, P., Ashani, Y., Khare, S. D., Oberdorfer, G., Leader, H., et al. (2013). Engineering V-type nerve agents detoxifying enzymes using computationally focused libraries. ACS Chem. Biol. 8, 2394-2403. doi: $10.1021 / \mathrm{cb} 4004892$

Costa, L. G., McDonald, B. E., Murphy, S. D., Omenn, G. S., Richter, R. J., Motulsky, A. G., et al. (1990). Serum paraoxonase and its influence on paraoxon and chlorpyrifos-oxon toxicity in rats. Toxicol. Appl. Pharmacol. 103, 66-76. doi: 10.1016/0041-008X(90)90263-T

Cousin, X., Hotelier, T., Lievin, P., Toutant, J. P., and Chatonnet, A. (1996). A cholinesterase genes server (ESTHER): a database of cholinesteraserelated sequences for multiple alignments, phylogenetic relationships, mutations and structural data retrieval. Nucleic Acids Res. 24, 132-136. doi: $10.1093 /$ nar/24.1.132

Dalby, P. A. (2003). Optimising enzyme function by directed evolution. Curr. Opin. Struct. Biol. 13, 500-505. doi: 10.1016/S0959-440X(03)00101-5

Doctor, B. P., and Saxena, A. (2005). Bioscavengers for the protection of humans against organophosphate toxicity. Chem. Biol. Interact. 157-158, 167-171. doi: 10.1016/j.cbi.2005.10.024 
Ellman, G. L., Courtney, K. D., Andres, V. Jr., and Feather-Stone, R. M. (1961). A new and rapid colorimetric determination of acetylcholinesterase activity. Biochem. Pharmacol. 7, 88-95. doi: 10.1016/0006-2952(61)90145-9

Fawcett, W. P., Aracava, Y., Adler, M., Pereira, E. F., and Albuquerque, E. X. (2009). Acute toxicity of organophosphorus compounds in guinea pigs is sexand age-dependent and cannot be solely accounted for by acetylcholinesterase inhibition. J. Pharmacol. Exp. Ther. 328, 516-524. doi: 10.1124/jpet.108. 146639

Fleming, C. D., Edwards, C. C., Kirby, S. D., Maxwell, D. M., Potter, P. M., Cerasoli, D. M., et al. (2007). Crystal structures of human carboxylesterase 1 in covalent complexes with the chemical warfare agents soman and tabun. Biochemistry 46 , 5063-5071. doi: 10.1021/bi700246n

Geyer, B. C., Kannan, L., Garnaud, P. E., Broomfield, C. A., Cadieux, C. L., Cherni, I., et al. (2010). Plant-derived human butyrylcholinesterase, but not an organophosphorous-compound hydrolyzing variant thereof, protects rodents against nerve agents. Proc. Natl. Acad. Sci. U.S.A. 107, 20251-20256. doi: 10.1073/pnas.1009021107

Giver, L., Gershenson, A., Freskgard, P. O., and Arnold, F. H. (1998). Directed evolution of a thermostable esterase. Proc. Natl. Acad. Sci. U.S.A. 95, 12809-12813. doi: 10.1073/pnas.95.22.12809

Goldsmith, M., and Tawfik, D. S. (2013). "Methods in protein design," in Enzyme Engineering by Targeted Libraries, Chapter 12, 1st Edn., ed Amy E. Keating (Amsterdam: Academic Press/Elsevier), 257-283.

Hanozet, G., Pircher, H. P., Vanni, P., Oesch, B., and Semenza, G. (1981). An example of enzyme hysteresis. The slow and tight interaction of some fully competitive inhibitors with small intestinal sucrase. J. Biol. Chem. 256, 3703-3711.

Hemmert, A. C., Otto, T. C., Wierdl, M., Edwards, C. C., Fleming, C. D., MacDonald, M., et al. (2010). Human carboxylesterase 1 stereoselectively binds the nerve agent cyclosarin and spontaneously hydrolyzes the nerve agent sarin. Mol. Pharmacol. 77, 508-516. doi: 10.1124/mol.109.062356

Hornberg, A., Tunemalm, A. K., and Ekstrom, F. (2007). Crystal structures of acetylcholinesterase in complex with organophosphorus compounds suggest that the acyl pocket modulates the aging reaction by precluding the formation of the trigonal bipyramidal transition state. Biochemistry 46, 4815-4825. doi: 10.1021/bi0621361

Hosea, N. A., Radic, Z., Tsigelny, I., Berman, H. A., Quinn, D. M., and Taylor, P. (1996). Aspartate 74 as a primary determinant in acetylcholinesterase governing specificity to cationic organophosphonates. Biochemistry 35, 10995-11004. doi: 10.1021/bi9611220

Ilyushin, D. G., Haertley, O. M., Bobik, T. V., Shamborant, O. G., Surina, E. A., Knorre, V. D., et al. (2013). Recombinant human butyrylcholinesterase as a new-age bioscavenger drug: development of the expression system. Acta Naturae 5, 73-84.

Imai, T., Taketani, M., Shii, M., Hosokawa, M., and Chiba, K. (2006). Substrate specificity of carboxylesterase isozymes and their contribution to hydrolase activity in human liver and small intestine. Drug Metab. Dispos. 34, 1734-1741. doi: 10.1124/dmd.106.009381

Kirby, S. D., Norris, J. R., Richard, S. J., Bahnson, B. J., and Cerasoli, D. M. (2013). Human paraoxonase double mutants hydrolyze V and G class organophosphorus nerve agents. Chem. Biol. Interact. 203, 181-185. doi: 10.1016/j.cbi.2012.10.023

Kitz, R., and Wilson, I. B. (1962). Esters of methanesulfonic acid as irreversible inhibitors of acetylcholinesterase. J. Biol. Chem. 237, 3245-3249.

Kua, J., Zhang, Y., Eslami, A. C., Butler, J. R., and McCammon, J. A. (2003). Studying the roles of W86, E202, and Y337 in binding of acetylcholine to acetylcholinesterase using a combined molecular dynamics and multiple docking approach. Protein Sci. 12, 2675-2684. doi: 10.1110/ps.03318603

Lenz, D. E., Yeung, D., Smith, J. R., Sweeney, R. E., Lumley, L. A., and Cerasoli, D. M. (2007). Stoichiometric and catalytic scavengers as protection against nerve agent toxicity: a mini review. Toxicology 233, 31-39. doi: 10.1016/j.tox.2006. 11.066

Li, H., Schopfer, L. M., Nachon, F., Froment, M. T., Masson, P., and Lockridge, O. (2007). Aging pathways for organophosphate-inhibited human butyrylcholinesterase, including novel pathways for isomalathion, resolved by mass spectrometry. Toxicol. Sci. 100, 136-145. doi: 10.1093/toxsci/ $\mathrm{kfm} 215$

Li, W. F., Furlong, C. E., and Costa, L. G. (1995). Paraoxonase protects against chlorpyrifos toxicity in mice. Toxicol. Lett. 76, 219-226. doi: 10.1016/03784274(95)80006-Y
Lockridge, O., Blong, R. M., Masson, P., Froment, M. T., Millard, C. B., and Broomfield, C. A. (1997). A single amino acid substitution, Gly117His, confers phosphotriesterase (organophosphorus acid anhydride hydrolase) activity on human butyrylcholinesterase. Biochemistry 36, 786-795. doi: 10.1021/bi961412g

Lushchekina, S. V., Nemukhin, A. V., Varfolomeev, S. D., and Masson, P. (2014). Molecular modeling evidence for His438 flip in the mechanism of butyrylcholinesterase hysteretic behavior. J. Mol. Neurosci. 52, 434-445. doi: 10.1007/s12031-013-0178-2

Main, A. R. (1979). Mode of action of anticholinesterases. Pharmac. Ther. 6, 579-628. doi: 10.1016/0163-7258(79)90066-4

Masson, P. (2012). Time-dependent kinetic complexities in cholinesterasecatalyzed reactions. Biochemistry (Mosc.) 77, 1147-1161. doi: 10.1134/S0006297912100070

Masson, P., Adkins, S., Pham-Trong, P., and Lockridge, O. (1992). "Expression and refolding of functional human butyrylcholinesterase from E. Coli," in Multidisciplinary Approaches to Cholinesterase Functions, eds A. Shafferman and B. Velan (New York, NY: Springer), 49-52. doi: 10.1007/978-1-4615-3046-6_6

Masson, P., Fortier, P. L., Albaret, C., Froment, M. T., Bartels, C. F., and Lockridge, O. (1997a). Aging of di-isopropyl-phosphorylated human butyrylcholinesterase. Biochem. J. 327(Pt 2), 601-607.

Masson, P., Froment, M. T., Gillon, E., Nachon, F., Lockridge, O., and Schopfer, L. M. (2007). Hydrolysis of oxo- and thio-esters by human butyrylcholinesterase. Biochim. Biophys. Acta 1774, 16-34. doi: 10.1016/j.bbapap.2006.10.012

Masson, P., Legrand, P., Bartels, C. F., Froment, M. T., Schopfer, L. M., and Lockridge, O. (1997b). Role of aspartate 70 and tryptophan 82 in binding of succinyldithiocholine to human butyrylcholinesterase. Biochemistry 36 , 2266-2277. doi: 10.1021/bi962484a

Masson, P., and Lockridge, O. (2010). Butyrylcholinesterase for protection from organophosphorus poisons: catalytic complexities and hysteretic behavior. Arch. Biochem. Biophys. 494, 107-120. doi: 10.1016/j.abb.2009.12.005

Masson, P., Nachon, F., and Lockridge, O. (2010). Structural approach to the aging of phosphylated cholinesterases. Chem. Biol. Interact. 187, 157-162. doi: 10.1016/j.cbi.2010.03.027

Masson, P., and Rochu, D. (2009). Catalytic bioscavengers against toxic esters, an alternative approach for prophylaxis and treatments of poisonings. Acta Naturae 1, 68-79.

Masson, P., Schopfer, L. M., Froment, M. T., Debouzy, J. C., Nachon, F., Gillon, E., et al. (2005). Hysteresis of butyrylcholinesterase in the approach to steady-state kinetics. Chem. Biol. Interact. 157-158, 143-152. doi: 10.1016/j.cbi.2005.10.019

Mata, D. G., Rezk, P., Sabnekar, P., Cerasoli, D. M., and Chilukuri, N. (2014) Investigation of evolved paraoxonase-1 variants for prevention of organophosphorous pesticide compound intoxication. J. Pharmacol. Exp. Ther. 349, 549-558. doi: 10.1124/jpet.114.213645

Maxwell, D. M., and Koplovitz, I. (1990). Effect of endogenous carboxylesterase on HI-6 protection against soman toxicity. J. Pharmacol. Exp. Ther. 254, 440-444.

Michel, H. O., Hackley, B. E. Jr., Berkowitz, L., List, G., Hackley, E. B., Gillilan, W., et al. (1967). Ageing and dealkylation of Soman (pinacolylmethylphosphonofluoridate)-inactivated eel cholinesterase. Arch. Biochem. Biophys. 121, 29-34. doi: 10.1016/0003-9861(67)90006-9

Millard, C. B., Kryger, G., Ordentlich, A., Greenblatt, H. M., Harel, M., Raves, M. L., et al. (1999). Crystal structures of aged phosphonylated acetylcholinesterase: nerve agent reaction products at the atomic level. Biochemistry 38, 7032-7039. doi: 10.1021/bi9826781

Millard, C. B., Lockridge, O., and Broomfield, C. A. (1995a). Design and expression of organophosphorus acid anhydride hydrolase activity in human butyrylcholinesterase. Biochemistry 34, 15925-15933. doi: 10.1021/bi00049a007

Millard, C. B., Lockridge, O., and Broomfield, C. A. (1995b). Presentation at Structure and Function of Regulatory Proteins Bethesda: MD, NIH, Fogarty International Center.

Millard, C. B., Lockridge, O., and Broomfield, C. A. (1998). Organophosphorus acid anhydride hydrolase activity in human butyrylcholinesterase: synergy results in a somanase. Biochemistry 37, 237-247. doi: 10.1021/bi972057c

Mumford, H., and Troyer, J. K. (2011). Post-exposure therapy with recombinant human BuChE following percutaneous VX challenge in guinea-pigs. Toxicol. Lett. 206, 29-34. doi: 10.1016/j.toxlet.2011.05.1016

Nachon, F., Brazzolotto, X., Trovaslet, M., and Masson, P. (2013). Progress in the development of enzyme-based nerve agent bioscavengers. Chem. Biol. Interact 206, 536-544. doi: 10.1016/j.cbi.2013.06.012 
Nachon, F., Carletti, E., Wandhammer, M., Nicolet, Y., Schopfer, L. M., Masson, P., et al. (2011). X-ray crystallographic snapshots of reaction intermediates in the G117H mutant of human butyrylcholinesterase, a nerve agent target engineered into a catalytic bioscavenger. Biochem. J. 434, 73-82. doi: 10.1042/BJ20101648

Newcomb, R. D., Campbell, P. M., Ollis, D. L., Cheah, E., Russell, R. J., and Oakeshott, J. G. (1997). A single amino acid substitution converts a carboxylesterase to an organophosphorus hydrolase and confers insecticide resistance on a blowfly. Proc. Natl. Acad. Sci. U.S.A. 94, 7464-7468. doi: 10.1073/pnas.94.14.7464

Nicolet, Y., Lockridge, O., Masson, P., Fontecilla-Camps, J. C., and Nachon, F. (2003). Crystal structure of human butyrylcholinesterase and of its complexes with substrate and products. J. Biol. Chem. 278, 41141-41147. doi: 10.1074/jbc.M210241200

Oppenoorth, F. J., and van Asperen. (1960). Allelic genes in the housefly producing modified enzymes that cause organophosphate resistance. Science 132, 298-299. doi: 10.1126/science.132.3422.298

Ordentlich, A., Barak, D., Kronman, C., Ariel, N., Segall, Y., Velan, B., et al. (1995). Contribution of aromatic moieties of tyrosine 133 and of the anionic subsite tryptophan 86 to catalytic efficiency and allosteric modulation of acetylcholinesterase. J. Biol. Chem. 270, 2082-2091. doi: 10.1074/jbc.270. 5.2082

Ordentlich, A., Barak, D., Kronman, C., Ariel, N., Segall, Y., Velan, B., et al. (1998). Functional characteristics of the oxyanion hole in human acetylcholinesterase. J. Biol. Chem. 273, 19509-19517. doi: 10.1074/jbc.273.31.19509

Ordentlich, A., Barak, D., Kronman, C., Flashner, Y., Leitner, M., Segall, Y., et al. (1993). Dissection of the human acetylcholinesterase active center determinants of substrate specificity. Identification of residues constituting the anionic site, the hydrophobic site, and the acyl pocket. J. Biol. Chem. 268, 17083-17095.

Otto, T. C., Kasten, S. A., Kovaleva, E., Liu, Z., Buchman, G., Tolosa, M., et al. (2010). Purification and characterization of functional human paraoxonase1 expressed in Trichoplusia ni larvae. Chem. Biol. Interact. 187, 388-392. doi: 10.1016/j.cbi.2010.02.022

Poyot, T., Nachon, F., Froment, M. T., Loiodice, M., Wieseler, S., Schopfer, L. M., et al. (2006). Mutant of Bungarus fasciatus acetylcholinesterase with low affinity and low hydrolase activity toward organophosphorus esters. Biochim. Biophys. Acta 1764, 1470-1478. doi: 10.1016/j.bbapap.2006.07.008

Sarkar, G., and Sommer, S. S. (1990). The "megaprimer" method of site-directed mutagenesis. Biotechniques 8, 404-407.

Satoh, T., and Hosokawa, M. (1995). Molecular aspects of carboxylesterase isoforms in comparison with other esterases. Toxicol. Lett. 82-83, 439-445. doi: 10.1016/0378-4274(95)03493-5

Saxena, A., Sun, W., Luo, C., Myers, T. M., Koplovitz, I., Lenz, D. E., et al. (2006). Bioscavenger for protection from toxicity of organophosphorus compounds. J. Mol. Neurosci. 30, 145-148. doi: 10.1385/JMN:30:1:145

Schopfer, L. M., Boeck, A. T., Broomfield, C. A., and Lockridge, O. (2004). Mutants of human butyrylcholinesterase with organophosphate hydrolase activity; evidence that His117 is a general base catalyst for hydrolysis of echothiophate. J. Med. Chem. Def. 2, 1-21.

Shafferman, A., Ordentlich, A., Barak, D., Stein, D., Ariel, N., and Velan, B. (1996). Aging of phosphylated human acetylcholinesterase: catalytic processes medi-

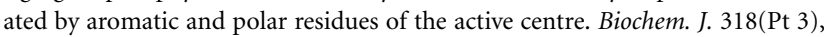
833-840.

Shih, T. M., Duniho, S. M., and McDonough, J. H. (2003). Control of nerve agent-induced seizures is critical for neuroprotection and survival. Toxicol. Appl. Pharmacol. 188, 69-80. doi: 10.1016/S0041-008X(03)00019-X

Spiller, B., Gershenson, A., Arnold, F. H., and Stevens, R. C. (1999). A structural view of evolutionary divergence. Proc. Natl. Acad. Sci. U.S.A. 96, 12305-12310. doi: 10.1073/pnas.96.22.12305

Temeyer, K. B., Brake, D. K., and Schlechte, K. G. (2012). Acetylcholinesterase of Haematobia irritans (Diptera: Muscidae): baculovirus expression, biochemical properties, and organophosphate insensitivity of the G262A mutant. J. Med. Entomol. 49, 589-594. doi: 10.1603/ME11211

Trovaslet-Leroy, M., Musilova, L., Renault, F., Brazzolotto, X., Misik, J., Novotny, L., et al. (2011). Organophosphate hydrolases as catalytic bioscavengers of organophosphorus nerve agents. Toxicol. Lett. 206, 14-23. doi: 10.1016/j.toxlet.2011.05.1041

Uto, I. S., and Brewer, J. M. (2008). Hysteresis on heating and cooling of E. coli alkaline phosphatase. Protein Pept. Lett. 15, 516-520. doi: 10.2174/092986608784567582

Valiyaveettil, M., Alamneh, Y., Rezk, P., Biggemann, L., Perkins, M. W., Sciuto, A. M., et al. (2011). Protective efficacy of catalytic bioscavenger, paraoxonase 1 against sarin and soman exposure in guinea pigs. Biochem. Pharmacol. 81, 800-809. doi: 10.1016/j.bcp.2010.12.024

Wang, E. I., and Braid, P. E. (1967). Oxime reactivation of diethylphosphoryl human serum cholinesterase. J. Biol. Chem. 242, 2683-2687.

Wang, Y., Boeck, A. T., Duysen, E. G., Van, K. M., Saunders, T. L., and Lockridge, O. (2004). Resistance to organophosphorus agent toxicity in transgenic mice expressing the $\mathrm{G} 117 \mathrm{H}$ mutant of human butyrylcholinesterase. Toxicol. Appl. Pharmacol. 196, 356-366. doi: 10.1016/j.taap.2003.12.018

Warshel, A. (2003). Computer simulations of enzyme catalysis: methods, progress, and insights. Annu. Rev. Biophys. Biomol. Struct. 32, 425-443. doi: 10.1146/annurev.biophys.32.110601.141807

Xie, W., Altamirano, C. V., Bartels, C. F., Speirs, R. J., Cashman, J. R., and Lockridge, O. (1999). An improved cocaine hydrolase: the A328Y mutant of human butyrylcholinesterase is 4-fold more efficient. Mol. Pharmacol. 55, 83-91.

Yao, Y., Liu, J., and Zhan, C. G. (2012). Why does the G117H mutation considerably improve the activity of human butyrylcholinesterase against sarin? Insights from quantum mechanical/molecular mechanical free energy calculations. Biochemistry 51, 8980-8992. doi: 10.1021/bi3009246

Zhang, N. N., Liu, C. F., Yang, F., Dong, S. L., and Han, Z. J. (2012). Resistance mechanisms to chlorpyrifos and F392W mutation frequencies in the acetylcholine esterase acel allele of field populations of the tobacco whitefly, Bemisia tabaci in China. J. Insect Sci. 12, 41. doi: 10.1673/031. 012.4101

Zhang, Y., Kua, J., and McCammon, J. A. (2002). Role of the catalytic triad and oxyanion hole in acetylcholinesterase catalysis: an $a b$ initio QM/MM study. J Am. Chem. Soc. 124, 10572-10577. doi: 10.1021/ja020243m

Zheng, F., and Zhan, C. G. (2008). Structure-and-mechanism-based design and discovery of therapeutics for cocaine overdose and addiction. Org. Biomol. Chem. 6, 836-843. doi: 10.1039/b716268e

Conflict of Interest Statement: While the Guest Associate Editor Carissa M. Soto and the author Patricia. M. Legler are affiliated to the same Institution, the review process was handled objectively as established by the journal guidelines. The authors declare that the research was conducted in the absence of any commercial or financial relationships that could be construed as a potential conflict of interest.

Received: 13 March 2014; accepted: 19 June 2014; published online: 16 July 2014. Citation: Legler PM, Boisvert SM, Compton JR and Millard CB (2014) Development of organophosphate hydrolase activity in a bacterial homolog of human cholinesterase. Front. Chem. 2:46. doi: 10.3389/fchem.2014.00046

This article was submitted to Chemical Biology, a section of the journal Frontiers in Chemistry.

Copyright (c) 2014 Legler, Boisvert, Compton and Millard. This is an open-access article distributed under the terms of the Creative Commons Attribution License (CC BY). The use, distribution or reproduction in other forums is permitted, provided the original author(s) or licensor are credited and that the original publication in this journal is cited, in accordance with accepted academic practice. No use, distribution or reproduction is permitted which does not comply with these terms. 